\title{
Mastication in the Tuatara, Sphenodon punctatus (Reptilia: Rhynchocephalia): Structure and Activity of the Motor System
}

\author{
G. C. GORNIAK, H. I, ROSENRERG, ANI CARI. GANS \\ Divrsion of Biological Sciences, The University of Michigun. Ann Artor, \\ Michigan 43109
}

\begin{abstract}
The masticatory pattern of Sphenodon punctatus, the sole remaining rhynchocephalian, now restricted to islands off the coast of New Zealand, has been analyzed by detailed anatomy, cinematography, cinefluoroscopy, and electromyography. Food reduction consists of a closing, crushing bite followed by a propalineal sliding of the dentary row between the maxillary and patatine ones. The large, fleshy tongue can be protruded to pick up small prey, and also plays a major role in prey manipulation. The rotational closing movement of the jaw, supporting the basic crushing movement, is induced by the main adductor musculature. It is followed by a propalineal anterior displacement relying heavily on the action of the $M$. pterygoideus. The fiber lengths of the several muscles reflect the extent of shortening. The most obvious modification appears in the $M$. pterygoideus, which contains a central slip of pinnately arranged short fibers that act at a period different from that of the rest of the muscle; their action increases the power during the terminai portion of the propalineal phase. This also allows the animal to use its short teeth in an effective shearing bite that cuts fragments off large prey.

The action of single cusped dentary teeth acting between the maxillary and palatine tooth rows provides a translational crushing-cutting action that may be an analog of the mammalian molar pattern. However, this strictly fore-aft slide does not incorporate capacity for later development of lateral movement.
\end{abstract}

As the sole Recent representative of the order Rhynchocephalia, the tuatara Spheno. don punctatus has been the subject of a disproportionately large number of anatomic studies (see Dawbin. '62: Robb, 73). The skull of Sphenodon differs from that of other lepidosaurians in being fully diapsid. A quadrato. jugal bone, a squamosal-jugal brace, and a fixed quadrate are retained, although there is some question about the degree of cranial kinesis (Versluys, '12; Kuhn-Schnyder, "54; Ostrom, 62; Iordansky, '66; Rieppel, '78). Both the dentitional pattern (Robinson, 76 ) and the cephalic musculature (Haas, 73; PoglayenNeuwall, 53) show further differences. Earlier investigations, both descriptive and functional, relied on preserved material. More recently, field investigations (Crook, '75; Gans, 82) and laboratory studies of living specimens (e.g., Hill and Dawbin, 69; McDonald and Heath, '71; Gans and Wever, '76. Ireland and Gans, 77) have begun to increase our understanding of the physiology and behavior of the tuatara (Robb, '77). The present report of the relation of cranial architecture, musculature, and dentitional patterns to feeding behavior and muscle action in the tuatara provides a base line for comparisons among lepidosaurians.

Lepidosaurians feed in various ways and their varied feeding behaviors are reflected in the structures they use. Snakes swallow their prey whole by means of alternating, unilateral movements of their highly kinetic skulls (Cundall and Gans, '79; Gans, '61\%. Amphisbaenians bite into their prey, ripping pieces loose by rotation of the body (Gans, '74). Herbivorous lizards crop vegetation, then swallow it with minimal reduction (Throckmorton. 76). Carnivorous lizards chew small food items (Frazzetta, 62) or utilize inertial feeding to bolt down large prey (Gans, '61). Neither the occurrence nor the absence of cranial kinesis correlates clearly with particular feeding strategies.

The skull of Sphenodon differs from those of Recent lizards because it has two fixed and parallel rows of teeth on each side of the upper

\footnotetext{
Wurk carried out while FI.I. Hosenhork was Visiting Assuciate Pre iessur at The Unuersity of Michigan on leave from the Departunent of Biology, IInizersity of Calgar\}: Calgary, Alberta. Canada

'This paper is dedic:ated to the menory of Grorge llass in appreciation ul his profound contributions to the cephalic anatomy of Recent and fossil reptiles
} 
jaw. The lateral teeth of each set lie on the medial edge of the maxilla and the medial ones on the lateral edge of the palatine; between them they form a narrow tooth-fringed channel into which the mandibular tooth row closes. The teeth are subtriangular in profile, with the bases fused in series along each row. Keconstructions have suggested that sphenodontids reduce their food by powerful, relatively slow shearing bites (Gunther, 1867; Robinson, '73).

The origin of the difference between food processing by Sphenodon and lizards apparently dates back to the pre-Triassic separation between sphenodontid rhynchocephalians and carnivorous prolacertilians (Robinson, '73). The latter probably used weak, relatively fast. piercing bites. The dichotomy of masticatory patterns seems to have been sharpened further as the lizards lost the quadratojugal arcade and mobilized their quadrate bones istreptostyly): this permitted the swallowing of relatively larger prey. Sphenodon has a fully diapsid skull with a fixed quadrate and is apparently unable to increase the lateral distance between the jaw joints. It apparently compensates for the limited size of the bolus that may be swallowed by subdividing larger prey into manageable pieces.

Through the courtesy of the government of New Zealand, four living specimens of Sphenodon were avalable for study. We here describe how Sphenodon capture and masticate different prey and how the major muscles then drive their jaws. Analysis of some of the smaller muscular components is relegated to a second study.

\section{WATHRIALS AND METHOIS Specimens available}

The following animals were used in this study: For osteology, AMNH 75705, AMNH 89835 , CU 8568; for myology, two preserved but partially dissected (brains removed for neuroanatomic study) heads (CG 5369,5370) and one intact specimen (CG 5321); for observation of feeding movements three living specimens ttwo females, one male; weight range 582-822 $\mathrm{gm}$; CG 5320,5322, 5323); the last two were used for the electromyography.

\section{Dissection}

Photographs of all stages of dissection served as a basis for illustrations and descriptions. Contrast between muscle and the surrounding connective tissue was increased by use of an iodine solution (Bock and Shear, '72). Muscle terminology follows Haas (73).
The animal (female; weight $242 \mathrm{gm}$; snoutvent length $22.1 \mathrm{~cm}$ l used for myologic anal$y$ sis had died of a protozoan infection that left its muscles relaxed. Fixation was in $10 \%$ formalin about $2 \mathrm{hr}$. after death (time required for postmortem veterinary examinationl. An estimate of muscle weight, fiber and sarcomere lengths, and muscle architecture (Table il of the major masticatory muscles was obtained by 1) dissecting out the preserved muscles ion one side\}, 2$\}$ weighing each three times ibeing blotted dry bet ween each weighing), 3) immersing each in $30 \%$ nitric acid for three to five days to dissolve the connective tissue, and 4 । then placing them in $50 \%$ glycerol. The fiber arrangement of the muscles was then traced from camera lucida projection on a Wild dis. secting microscope. The length of five entire fibers from adjacent positions within the muscle was measured on a millimeter scale and ocu. lar micrometer on a dissecting microscope. Several fibers were then placed in glycerol on a microscope slide and examined under oil immersion. The overall length of 20 sets of 10 sarcomeres was measured for part of each muscle by means of a calibrated micrometer located in the ocular. The muscles were then washed with water and $70 \%$ alcohol, air-dried, and weighed to obtain dry weights of the fiber masses.

\section{Behavioral observations and movement records}

Specimens were observed while they were housed individually in large $(1 \mathrm{~m} \times 1 \mathrm{~m} \times 1 \mathrm{~m})$, screened, glass-fronted cages located in an airconditioned room maintained at $15^{\circ}-17^{\circ} \mathrm{C}$ and illuminated for $12 \mathrm{hr}$. periods by both GroLux and white fluorescent lamps. A heat lamp focused on one corner of the cage provided a basking site. Tuataras were fed crickets. cockroaches, and newly born mice that had been dusted with Pervinal vitamin powder. Fresh drinking water and pans large enough to let the animals immerse themselves were always available.

For detailed observations of feeding, tuataras were temporarily transferred to smaller cages or a table top and then conditioned to accept food manipulated by hand. Chilled crickets (length: $2.0-2.4 \mathrm{~cm}$; weight: $0.3-0.6 \mathrm{gm})$ and cockroaches (length: $2.8-3.0$ cm; weight: 0.5-0.7 gmi, as well as newly born (length: 3.5-4.0 cm; weight: $2.1-2.4 \mathrm{gm}$ ) and juvenile mice (length: $5.5-6.0 \mathrm{~cm}$; weight: $6.1-7.0 \mathrm{gm})$, were offered individually to facilitate observation and cinematography. Feeding sequences were filmed on $16-\mathrm{mm}$ film with a strobe-synchronized camera (Gans, '66) 
using either direct lateral or biangular lateralfrontal (mirror) views. Cineradiographs of one specimen were taken at the Museum of Comparative Zoology of Harvard University (courtesy of Professor F. Jenkins) with a Siemens cinefluoroscopy unit operated at 50 $\mathrm{kV}$ and $120 \mathrm{~mA}$. The Siemens image intensifier was filmed with an Auclair 16- $\mathrm{mm}$ camera at about 50 frames per second. All films were analyzed with a Lafayette $16-\mathrm{mm}$ analytical projector and a Vanguard motion analyzer.

\section{Mercury strain gauge records}

During many of the feeding sequences, a vertically directed mercury strain gauge was placed on one side of the head. Patches of Velcro were attached by contact adhesive to the skin over the postorbital-squamosal bar and to the midventral surface of the lower jaw. Complementary patches of Velcro were bonded to each end of the gauge. The gauge was then placed so that it was under slight tension when the mouth was closed.

\section{Electromyography}

FMGs were recorded from those masticatory muscles into which electrodes could be placed using bony landmarks and pal- pation. Because of the high risk to the animal involved, we recorded from the small and deep. ly positioned muscles of the head in only one specimen. The activity of the infrahyoid and suprahyoid muscles and of the muscles of the tongue is excluded.

Electrodes formed of $0.076-\mathrm{mm}$ Tefloninsulated stainless steel wire (Medwire Corp.) were inserted through the skin and into each muscle via 25-gauge hypodermic needles isee Gans and Gorniak, 80 , for details of electrode construction). The outside ends of the electrodes were soldered to Teflon-insulated silver wires placed into PE tubing or to earphone wires (later experiments) that were connected to cables leading to the preamplifiers by Amphenol Mighty-Mite circular connectors. The coating of the connecting wires was fixed to the animal by short patches of Velcro. This kept the leads from shifting and relieved strain on the electrodes.

EMG signals were amplified by means of Tektronix 122 and $26 \mathrm{~A} 2$ preamplifiers and Honeywell 117 amplifiers. FMG signals, strobe photocell outputs, and those from the mercury strain gauge amplifier were stored on a Honeywell 5600 intermediate-band tape recorder and simultaneously displayed on a

TABLF. 1. Wet und dry uhole muscle ueights in gramsl and ranges of the fither lengths fin mm/ of the major masticatory muscles of Sphenodon

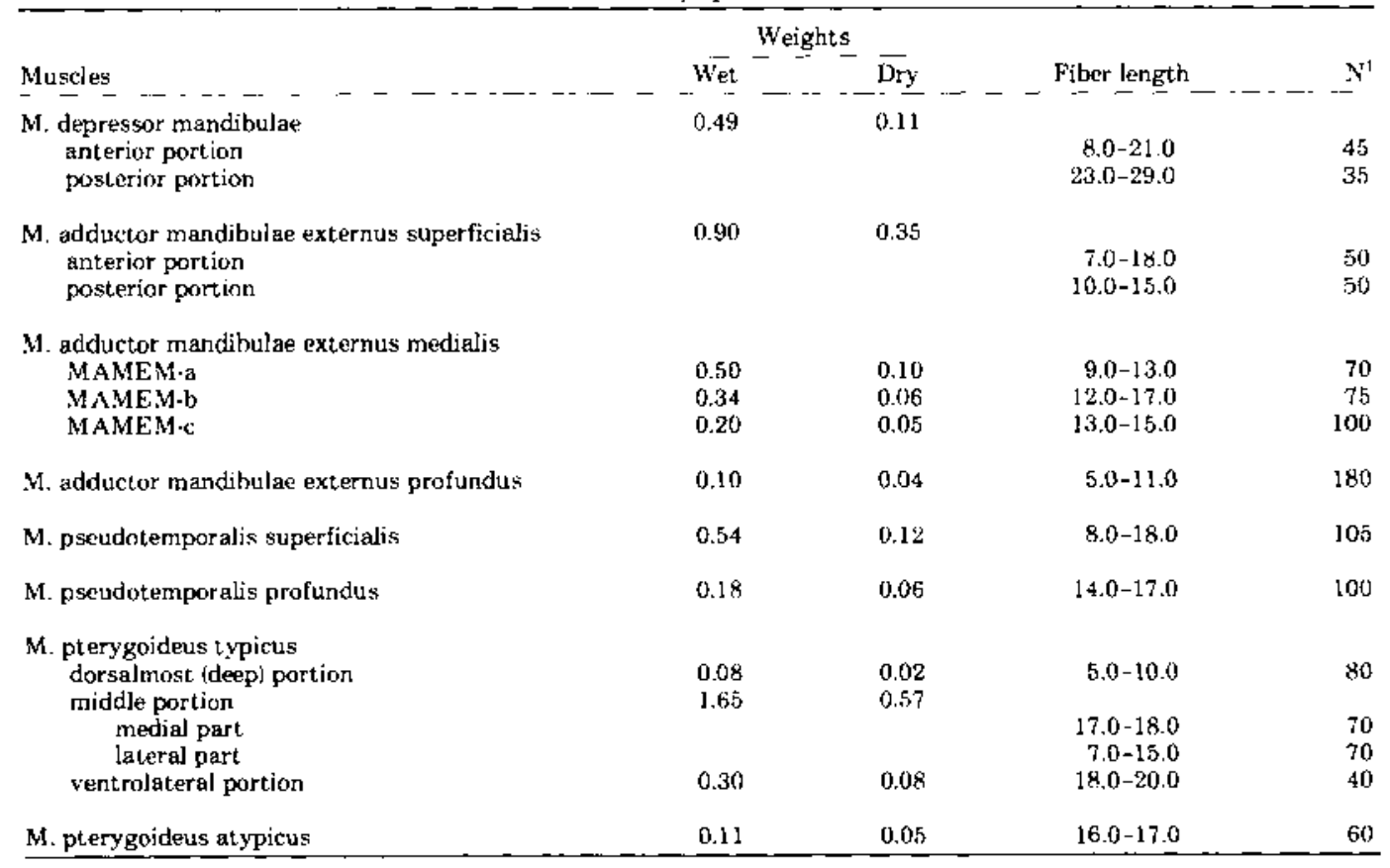

iN wquals mumber uf filiers mésisured 
Tektronix 565 oscilloscope and a Gould (Brush 481) multichannel chart recorder.

Animals were anesthesized by an intramuscular injection of Brevital Sodium (Eli Lilly: dosage: $1.2 \mathrm{mg} / \mathrm{kg}$ of body weight). After they had recovered from anesthesia, the conditioned animals were placed on a grounded stainless steel tray (moistened with saline solution) that was fixed in front of the chart recorder. A movie camera recorded a lateral view of the animal and the chart record showing EMG signals, a transducer signal, and a $\mathrm{l}-\mathrm{Hz}$ time signal.

Frame-by-frame projection of films allowed measurement of the displacement of the lower jaw. Velocity and acceleration were determined, first graphically and later by means of a computer. The displacement record was atso correlated with muscular activity and transducer signals. Up to seven simultaneous EMGs were digitized and processed by a Hewlett Packard 21MX minicomputer to obtain the number of spikes and their average amplitude for intervals correlated with the cine frames. Digitized records were stored on cassette tape and then displayed on a Tektronix 4051 Graphic Display System with 4662 digital plotter. Previous studies suggest that the product of the number of spikes times their amplitude correlates best with tension (Gorniak and Gans, '80); hence, this value was plotted for each muscle as a bar graph. The plot showed individual records as a percentage of the maximum value for each feeding sequence. Percentage graphs allow intersequence comparisons even though the level of amplification of EMGs has not been controlled in some experiments. Recent studies show that EMGs thus recorded and analyzed are highly repeatable (Gans and Gorniak, '801.

We here report on 80 feeding sequences combining EMG and strain gauge records, as well as on additional observations of EMGs without synchronized displacement recordings. Fifty-five of the feeding sequences were filmed, and 31 of these contain strobetriggered photocell outputs. EMGs with simultaneous movement records were obtained from the following muscles $1 \mathrm{~N}=$ the number of reduction sequences); anterior $(\mathrm{N}=17)$ and posterior $(N=38)$ portions of the $M$, depressor mandibulae; anterior $(\mathrm{N}=8)$ and posterior $(\mathrm{N}=8)$ portions of the $\mathrm{M}$. adductor mandibulae externus superficialis sensu stricto; anteromedial ( $N=59$ ), posterior $(N=14)$ and ventrolateral $(\mathrm{N}=6)$ ) portions of the $\mathrm{M}$. adductor mandibulae externus medialis: $M$. adductor mandibulae externus profundus $(\mathrm{N}=4) ; \mathrm{M}$ pseudotemporalis superficialis $(N=15) ; M$. pseudotemporalis profundus $(\mathrm{N}=5) ; \mathrm{M}$ pterygoideus atypicus $(\mathrm{N}=4)$ and the superficial $(\mathrm{N}=26)$ and deep $(\mathrm{N}=19)$ parts of the medial half of the middle portion of the $M$. pterygoideus typicus, as well as the superficial $(\mathrm{N}=5)$ and deep $(\mathrm{N}=5)$ parts of the lateral half of the middle portion and the ventrolateral portion of the M. pterygoideus typicus.

\section{RESULTS \\ General}

Detailed descriptions of the skull (Romer, 56), dentition (Robinson, 76), and cephalic musculature (Byerly '25; Haas, 73) of Sphenodon are already available. However, we here provide a brief description of the dentition and descriptions of the muscles from which recordings were made including their fiber lengths (Table 1) in order to provide a foundation for the interpretation of the movements they generate. Sarcomere lengths from different muscles are equivalent at $2.6 \mu \mathrm{m}$. Measurements of fiber and sarcomere lengths are for one speci. men and one side only.

Descriptions of the dentition and myology are followed by a description of the feeding movements observed when Sphenodon chews crickets, cockroaches, and mice of various sizes. Descriptions of the muscular activities recorded during reduction sequences are then presented.

\section{Dentition}

Sphenodon has a mandibular and maxillary pair of canine-like teeth and a maxillary pair of incisor-like leeth. The large canine-like mandibular teeth lie just posterolaterally to the mandibular symphysis; the smaller maxillary teeth lie posterior to the mandibular ones and are each preceded by three small conical teeth. All of these canine-like teeth are larger than the remaining marginal teeth. In frontal view. the mandibular canines slant slightly laterally and in lateral view slightly posteriorly: the maxillary canines extend directly ventrally. Both anterior and posterior surfaces of the canine-like teeth are rounded, whereas their medial and lateral surfaces are relatively flat.

The upper pair of incisor-like teeth protrudes straight downward from the premaxilla; these are the largest teeth. Each of the more posterior teeth generally has two pointed cusps, a small medial (which may be absent) and large lateral one. The anterior and lateral surfaces of these teeth are rounded, the 
posterior surface is flat, and the medial surface shows a sharp edge. In frontal projection, each tooth lies well medial to the quadratoarticular joint; the lateral margins of the teeth line up with the lateral margins of the palatine tooth rows and their medial margin ends just medial to the inner surface of the pterygoid flange. When the jaws are closed, the maxillary incisor-like teeth lie anterior to the mandibular symphysis and anteromedial to the canine-like mandibular teeth; neither pair contacts the other.

Sphenodon also has maxillary, palatine, and mandibular (dentary) marginal teeth. These: teeth are triangular in lateral view and increase. in size as one proceeds posteriorly along the tooth row. The medial side of the maxillary and mandibular teeth and the lateral side of the palatine teeth are flat; the opposite side is rounded. The rounded surface of the maxillary and palatine teeth flattens posteriorly, meets the flat surface of the tooth and forms a sharp posterior edge; their anterior surface is rounded. In contrast, both the anterior and posterior surfaces of the mandibular teeth are rounded. The maxillary and palatine teeth slant slightly posteriorly, whereas the mandibular teeth slant anteriorly.

The maxillary, palatine, and mandibular tooth rows diverge posterolaterally from the symphysis. The palatine teeth lie parallel to the posterior half of the maxillary tooth rows, forming a narrow trough between them. This trough is slightly wider posteriorly than anteriorly. The posterior mandibular teeth fit snugly within this trough and this fit restricts lateral movements of the mandible when the teeth are occluded.

\section{Weights}

\section{Mvology}

The air-dried weights of the masticating muscles of one side totaled $1.61 \mathrm{gm}$ (wet weights, blotted, totaled $5.39 \mathrm{gm})$. The $\mathrm{M}$. depressor mandibulae makes up $6.8 \%$ of the lotal dry weight, the M. pterygoideus atypicus $3.1 \%$ and the entire $M$. pterygoideus typicus $41.6 \%$. The remaining $48.5 \%$ comprises the superficial, medial, and deep adductors. The $M$. adductor mandibulae externus medialis makes up $13.0 \%$ of the total, the M, adductor mandibulae externus superficialis $21.7 \%$, the M. pseudotemporalis superficialis $7.5 \%$, the M. pseudotemporalis profundus $3.7 \%$, and the M. adductor mandibulae externus profundus $2,5 \%$. Thus, even though the M. pterygoideus typicus is the largest single muscle, its mass is less than that of all the adductors $1 \mathrm{com}$ pressors) combined. Appparentiy, the compressors are capable of generating the greatest forces.

\section{M. depressor mandibulae (MDM; Figs, 1,2)}

The posterior fibers of the $M$. depressor mandibulae originate from the dorsoposterior portion of the parietal and dorsal posteriormost part of the squamosal, and the anterior fibers originate from the posterior aspect of the dorsal process of the squamosal; some deep anterior fibers also originate from a middorsal section of connective tissue. The sharp difference in the origin and the difference in fiber lengths (Table 1) between the posterior half of the muscle and the anterior half suggests that the MDM may have an anterior and posterior subdivision, even though there is no obvious connective tissue plane separating them.

The posterior fibers first run laterad and slightly ventroposteriorly and then curve sharply posteriorly near the lower margin of the dorsal temporal fossa. These fibers curve around the posterior end of the jaw and insert on its ventral surface. The anterior fibers run ventroposteriorly and slightly laterad and then insert on the posterolateral end of the jaw. The superficial posterior and anterior fibers insert more ventrally on the mandible than the deeper fibers. The dorsal third of the depressor is thin, the middle third relatively thick, and the ventral third tapers towards the insertion. Loose connective tissue attaches the medial surface of the dorsal two-thirds of the muscle to underlying structures, whereas the ventral third is relatively free.

The lengths of the superficial fibers of the anterior portion of the MDM (range $19-21 \mathrm{~mm}$ ) are greater than those of its deep fibers (range 8-15 mml. In the posterior portion, the lengths of the superficial and deep fibers are similar (superficial: range $25-29 \mathrm{~mm}$; deep: range 23-25 mm), and their lengths are greater than those of the anterior portion. In both parts, the lengths of the superficial and deep fibers increase as one proceeds posteriorly; the increase is greatest in the deep fibers of the anterior portion.

M. adductor mandibulae externus superficialis sensu stricto (MAMES; Figs. 1,2)

The $M$. adductor externus superficialis sen$s u$ stricto fills the lateral part of the ventral temporal fossa and forms a bulge on the lateral surface of the posterior part of the lower jaw. It is covered by the lower temporal fascia and is 

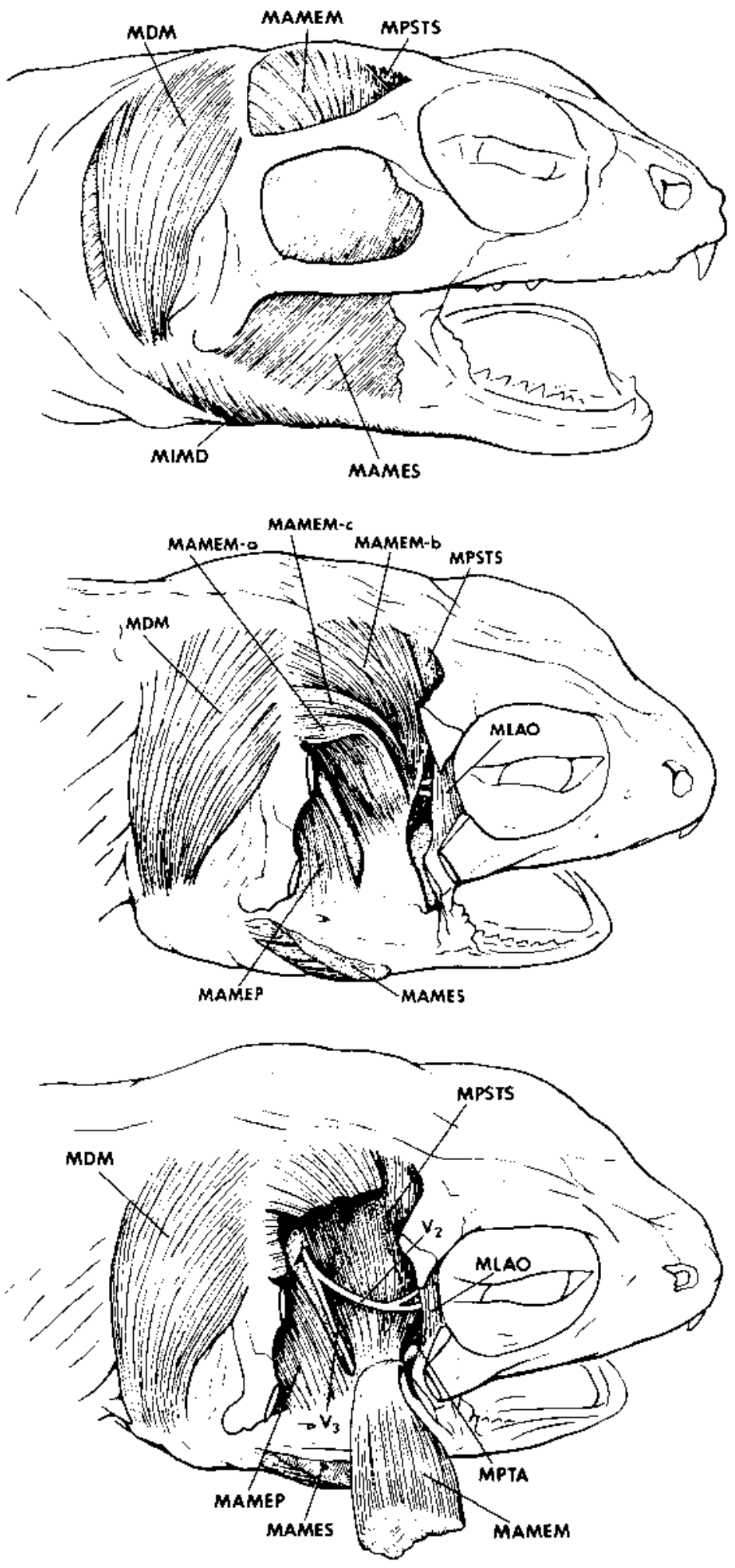
not immediately visible after removing of the skin. The MAMES originates from the medial surfaces of the postorbital and squamosal; the anterior one-fourth of the origin is fleshy, the deep portion of the middle half is fleshy, and the superficial part aponeurotic the aponeurosis is wide anteriorly and tapers posteriorly), and the posterior one-fourth of the origin is aponeurotic. The fibers pass in a posteroventrad and slightly laterad direction dorsal and medial to the jugal. Ventral to the jugal the fibers curve medially to insert along the lateral surface of the dentary, posterior to the mandibular tooth row. 'The most superficial fibers insert most ventral and the deepest fibers most dorsal on the dentary.

The superficial anteriormost fibers of the anterior one-fourth of the MAMES show the longest fiber lengths (range $17-18 \mathrm{~mm}$ ) and decrease thereafter $(13-14 \mathrm{~mm})$, whereas the underlying deep fibers of this part are short (range $7-10 \mathrm{~mm}$ ). As one proceeds posteriorly through the middle half of the MAMFS, the length of the superficial fibers originating from the wide aponeurosis first decreases to 11-12 $\mathrm{mm}$ but then increases to $14-15 \mathrm{~mm}$ as the aponeurosis tapers. In contrast, the length of the deep fibers of this portion first increases to $12-14 \mathrm{~mm}$ and then decreases to $10-12 \mathrm{~mm}$ posteriorly. In the posterior one-fourth of the MAMES, there is no significant difference between the lengths of the superficial and deep fibers. The lengths of these fibers range between $10-12 \mathrm{~mm}$ anteriorly and $8-9 \mathrm{~mm}$ posteriorly.

M. adductor mandibulae externus medialis (MAMEM: Figs, 1, 2)

The compound $\mathrm{M}$. adductor mandibulae externus medialis lies posterior to the $M$. pseudotemporalis superficialis. The muscle has fleshy origins, but all of its subdivisions in.

\footnotetext{
Fig. 1. Sphenodon punctafts. Top: Laural view of dis. sertion alter removal of skin and connective tissues. Yote that adductor nuscles are bound by the dorsal and ventral arches of the diapsid skull. Middle: Lateral view of dissec tion after romusal of both kony arches and most of the MAMES. Nere the subdivisions of the MAMEM and how this bulky muscle tapers to insert ontn the thin basal apo neurosis. Bottom: luateral view of the dissection after re moval of both bony arches. most of the MAMES. and dis. placement of the MA.V1k.M. Note the large MPS'ls and the relations of the maxillary $\left(\mathrm{V}_{2}\right)$ and mandibular $\left(\mathrm{V}_{3}\right.$ ! branches of the trigeminal nerve. MAMEM, .1. adductor mandibulae externus medialis; MAStE'P. M, adducor mandibulae texter nus proitundus: MAMES, M. adduct or mandibulac externus superficialis: MDM, M. depresser mandibulae: MIMD, M intermandibularis: MLAO, M. levacor anguli oris: MPSTS. M. pseudotemporalis superticlalis; MYTA, M. pterygoideus atypicus.
}

sert on the basal aponeurosis that lies deep to the MAMES. This aponeurosis is the insertion for several other adductors of the lower jaw, and transmits the forces to the dorsal margins of the coronoid and postcoronoid portion of the lower jaw. The bulk of the MAMEM fills the dorsal temporal fossa. It is difficult to see its individual heads, as the ventral half of the muscle is covered by loose connective tissue, by the MAMES, and by the upper temporal bar. In vivo, the components of the MAMEM may be located relative to the bony landmarks. Haas (73) lists five heads of the MAMEM (but only diagrams fourl: there appears to be a discrepancy between the labels used in his text description of the MAMEM and those in his diagrams. Only three $(a-c)$ heads were found in the present study and their labels follow the convention used in the diagrams.

The anteromedial head of the MAMEM (MAMFM-b) originates as a set of laterally and slightly anteriorly directed fibers from the dorsolateral surface of the parietal. A short distance from their origin, the superficial fibers of the anterior head curve sharply to run nearly straight ventrad and slightly anterior. $\mathrm{ly}$; the deeper fibers curve less sharply than the superficial ones and the deepest run nearly straight ventrolaterad. The superficial and deep fibers taper ventrally to insert on an anterodorsal extension of the basal aponeurosis with the anterior fibers inserting dor. sal to the posterior ones. The lengths of the superficial and deep fibers of the anterior portion of the MAMEM-b are similar (12-14 mm). In the posterior portion, the deep fibers $115-17$ $\mathrm{mm}$ ) are slightly longer than the superficial ones (14-16 mm) but both are longer than those anteriorly.

The posterior head (MAMEM-c) originates as a set of fibers that runs in a markedly anterolaterad direction from the dorsal, posterolateral surface of the parietal and the an. terodorsal surface of the squamosal. The superficial fibers then curve sharply ventrad, continue anteriorly, and pass deep to the postorbital bar and the MAMES. The deep fibers of the MAMEM-c run anteriorly and nearly straight ventrolaterad. The superficial and deep fibers converge ventrally to form a thin muscular sheet; the anterior fibers form the anterior part of this sheet and the posterior fibers the posterior part. The anterior part inserts dorsal to the posterior part on the lateral surface of the anterior and central portion of the basal aponeurosis. In the anterior part of the MAMEM-c, the deep fibers (14-15 mm) are slightly longer than the super ficial ones (13-14 

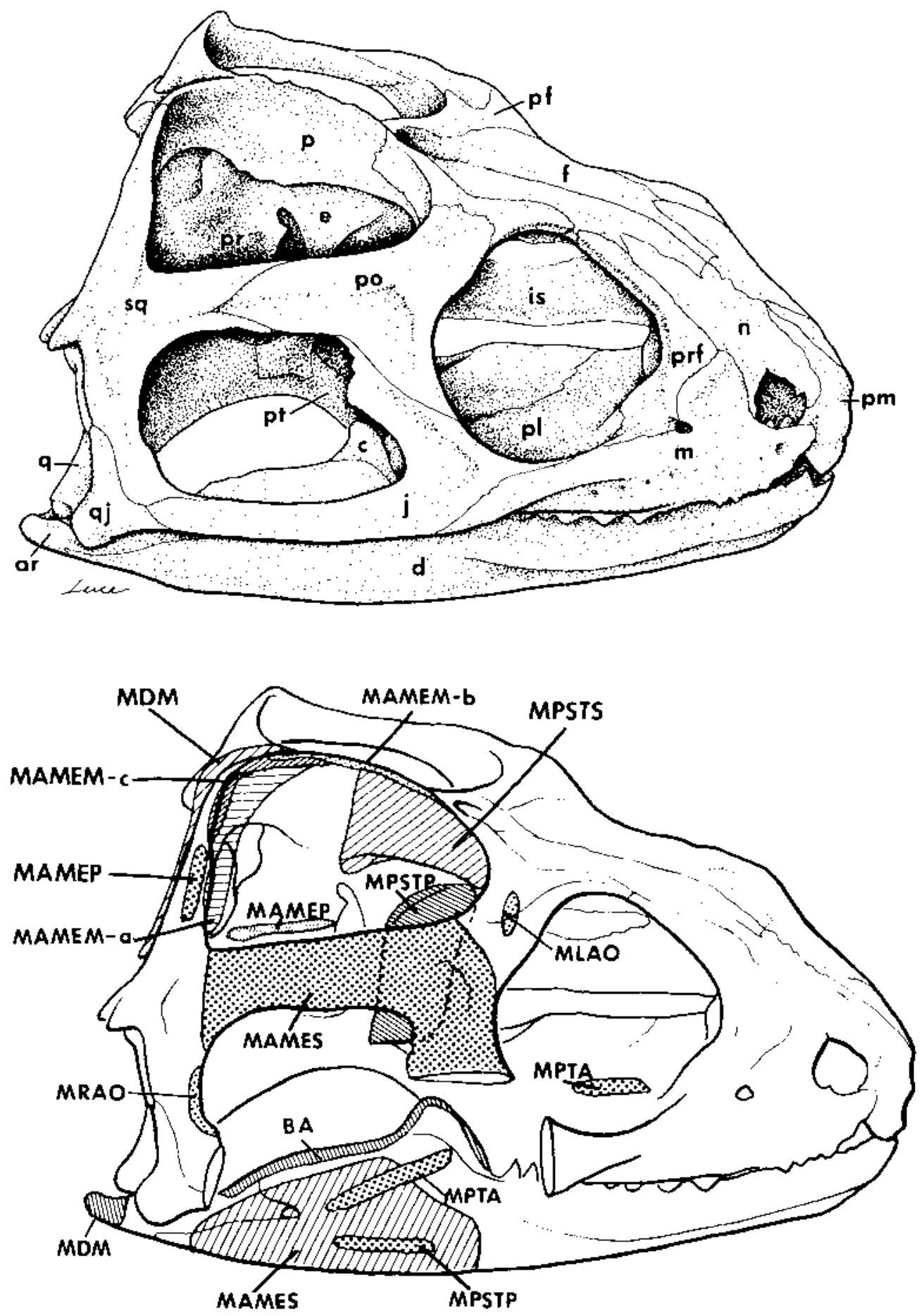

Fig. 2. Sphentulen punctutus. Top: I.ateral view of skull Yote fuljy diapsid skull having two temporal tenestrae com pletely encircled by bone. Bot tom: Lateral viow of the skul iwith lower arch removed! and lower jaw. 'The sites of attach. ment of centalis muscles are indicated. ar, articular; BA hasal aponeurosis; $c$ coronond process; di dentary" f. epipterygoid: f. frontal: is, interorbital septum; j. jugal; $m$. maxilla: MPSTP, M. pseudolemporalis protundus; n, nass] p. parietal; pf, postfrontal; pl, palatine; pm, premaxilla; po. postorbital: pr, prootic: prf, prefrontal; pt, pterygoidi q. quadrate: qj, quadratojugal; $5 q$. squamosal. For ecrm. pleteness, we show attachment sites of the M. levator angul oris (MLAO) and the $\mathrm{M}$. retractor anguli oris (MRAC). Other abbreviations as in Figure 
$\mathrm{mm})$. However, the lengths of the superficial and deep posterior fibers are similar to each other $(14-15 \mathrm{~mm})$ and similar in length to the deep fibers of the anterior portion.

The largest part of the MAMEM is the ventrolateral head (MAMEM-a) that originates from the posterolateral and posteroventral surface of the parietal and from the anterior sur. face of the dorsal process of the squamosal. The superficial fibers initially run in a marked. ly anterolateral direction, then curve sharply ventrad, continuing anteriorly to pass deep to the postorbital bar and MAMES. The deep fibers curve less than the superficial, running nearly straight ventrolateral and slightly anteriorly. The superficial fibers insert on the lateral surface and deep fibers on the medial surface of the anterior and central portion of the basal aponeurosis just ventral to the insertion of the anterior and middle heads. The anterior fibers of the MAMEM-a also insert dorsal to the posterior ones. The fibers of the anterior part of the MAMEM-a are shorter than those of the posterior part (anterior: 9-11 mm; posterior: 11-13 $\mathrm{mm}$ ). However, the lengths of the superficial and deep fibers of the anterior part are similar to each other as are those of the posterior part.

M. adductor mandibulae externus profundus (MAMEP; Figs. 1,2)

The $M_{\text {, adductor mandibulae externus pro- }}$ fundus lies deep to the MAMEM and posterior to the M. pseudotemporalis superficialis. It has a lateral head originating from the posterolateral surface of the prootic and a medial head originating from its anterolateral surface. The fibers of the lateral head pass ventrad and an. teriorly to converge onto a flat tendon, inserting on the medial surface of the posterior part of the basal aponeurosis. The anterior fibers of the medial head run almost directly ventrad to join the tendon of the lateral head. The posterior fibers of the medial head pass ventrad and slightly anteriorly to insert directly on the basal aponeurosis posterior to the insertion of its anterior fibers and those of the lateral head.

The anterior superficial fibers of the lateral head of the MAMEP are slightly shorter than the anterior deep fibers (superficial: $7-8 \mathrm{~mm}$; deep: $8-9 \mathrm{~mm}$. $\Lambda$ s one proceeds posteriorly, the length of the superficial fibers decreases (5-6 mm), whereas the lengths of the deep fibers remain relatively constant. The anterior superficial fibers of the medial head are also slightly shorter than those of its deep counterparts isuperficial: $6-7 \mathrm{~mm}$; deep: $7-8 \mathrm{~mm}$ ).
However, as one moves posteriorly the lengths of both the superficial and deep fibers increase and become similar to each other (superficial: 10-11 mm: deep: $9-11 \mathrm{~mm}$.

M. pseudotemporalis superficialis (MPSTS; Figs. 1, 2)

The anterodorsal portion of the M. pseudo temporalis superficialis is visible in the anterior corner of the dorsal temporal fossa, but most of the muscle lies deep to the MAMEM. The maxiliary division of the trigeminal nerve $\left(V_{2}\right)$ crosses the lateral face of the MPSTS and the mandibular branch of the trigeminal nerve $(\mathrm{V}, \mathrm{f}$ lies against its posterior margin.

The MPSTS originates from the posterior part of the postfrontal, the anterolateral part of the parietal, and the dorsoposterior part of the epipterygoid. Its anterior fibers initially pass ventrad and slightly anterolaterad dorsal to the postorbital, but then curve medially deep to the postorbital to run nearly straight ventrad. The anterior fibers converge to insert on the medial surface of a lendinous extension of the anterior part of the basal aponeurosis. The central and posterior fibers also run ven. trad and slightly laterad dorsal to the postorbital and then curve slightly medially ventral to it. However, the orientation of these fibers becomes progressively more anteriad as one moves caudally. The central fibers insert onto the anterior tendinous extension, ventral and posterior to the anterior fibers. The posterior fibers insert directly onto the medial surface of the anterior and central portion of the basal aponeurosis. The most superficial of the anterior, central, and posterior fibers insert most dorsally and the deepest fibers most ventrally.

The superficial anteriormost fibers of the MPSTS are longer than the derp ones (superficial: 17-18 mm: deep: 14-15 mm). As one moves posteriorly, the lengths of the superficial fibers remain relatively constant until the posterior margin of the MPSTS, where the fiber lengths decrease to $15 \mathrm{~mm}$. In contrast, the length of the deep fibers first increases (15-17 $\mathrm{mm}$ ) but then decreases $(11-8 \mathrm{~mm})$ as the posterior border of the muscle is reached.

M. pseudotemporalis profundus (MPSTP; Fig. 2)

The M. pseudotemporalis profundus is composed of a long lateral and a short medial part and lies between the MPSTS and the epipterygoid bone. The mandibular branch of the trigeminal nerve separates the posterior margin of the MPSTP from the anterior margin of the 
M. adductor mandibulae externus profundus. The lateral part originates deep to the anterior portion of the MPSTS from the ventroanterior region of the parietal and the dorsoanterior part of the epipterygoid. 'T'he medial part of the MPSTP lies deep to the lateral part and originates from the anterior part of the epipterygoid and the posterior part of the membranous braincase. 'The fibers of the lateral part pass ventroposteriorly and slightly laterad, whereas those of the medial part pass posterolaterad and slightly ventrad. 'The lateral and medial parts join near the upper margin of the mandible and the fibers then run ventroposteriorly and slightly laterad to insert on the ventromedial surfuce of the dentary, ventral to the coronoid process.

The lengths of the anteriormost and posteriormost fibers of the lateral part are similar (14-15 mm), as are the lengths of the anterior and posterior fibers of the medial part (14-15 $\mathrm{mm}$ ). However, the fibers in the middle of the lateral part are longer (16-17 mm) than those at its anterior and posterior margins.

\section{M. pterygoideus typicus (MP'TT; Fig. 31}

The bulky $M$. pterygoideus typicus has a complicated internal architecture. It may be subdivided into 1) a dorsalmost (deepl portion, 2) a middle portion, and 3) a ventrolateral one. Haas's brief description (1973) of this muscle only mentions its several bony points of attachment.

The dorsalmost (deepl portion of the MPTT fills the ventral half of the space lying medial to the pterygoid and pterygoid wing of the quadrate. The muscle originates from the anterodorsal region of the medial surface of the pterygoid. From here its fibers run sharply ventrad and curve slightly posterolaterally to insert on the dorsal surface of the posteromedial end of the lower jaw by means of fine tendons and fleshy attachment.

The fibers of the dorsalmost portion of the MPrT' are short dorsally and ventrally and long in the center of the muscle. As one moves dorsally, the length of the fibers increases from 5-6 mm iventral) to $8-10 \mathrm{~mm}$ but then decreases to $6-7 \mathrm{~mm}$.

The middle portion is the bulkiest part of the M PTTI. It bulges ventrally from the two sides to form a deep, narrow ridge in the roof of the posterior part of the oral cavity. The middle portion of the M P $\mathrm{P}^{\mathrm{T}} \mathrm{l}$ originates from the ventral and medial surface of the ectopterygoidpterygoid process (pterygoid flange), the medial margin and ventroposterior half of the pterygoid and the ventromedial process of the quadrate. Its superficial (i.e., ventral) fibers originate from the pterygoid by an aponeurosis, whereas the deeper fibers attach direct. ly. The middle portion of the MPTT may be subdivided into medial, intermediate, and lateral parts and each of these into superficial and deep fiber lavers.

The superficial fibers of the medial part show a parallel arrangement. These fibers first run posteromedially and slightly ventrad; thereafter they curve posterolaterad toward the ventroposterior margin of the mandible. The superficial fibers of the intermediate part also show bundles of parallel fibers that initially pass caudad, then turn sharply ventrad and slightly laterad to the ventral margin of the mandible; thereafter they curve sharply caudad and slightly ventrolaterad. The deep fibers of both these parts are parallel and pass straight posterolaterad and slightly caudad. Both superficial and deep fibers of the medial and intermediate parts converge posteriorly to insert on the medial surface of the posterior end of the lower $j a w, j u s t$ anterior to the insertion of the dorsal portion of the MP'JT.

As one moves farther laterad, the fiber arrangement of the MPTT changes from a parallel to a bipinnate one. This change in fiber arrangment is not obvious from a superficial ven. tral view, as the middle portion of the MP'l'l is covered partially by the ventrolateral portion. Haas ('73) does not describe this change in the MPTT of Sphenodon and no such condition has been mentioned for the MPTT of Uromastyx aegyptius (Throckmorton, '80). Varanus exanthematicus, Ctenosaura similis. and Tupinambis nigropunctata (Smith, '80).

This bipinnate arrangement marks the boundaries of the distinct lateral one-third of the MPTT. This lateral part is further subdivided into a lingual and buccal half by the insertion sites of the fibers. The medialmost $\mathrm{fi}$ bers of the lingual half are long, curve posteriolaterally, and insert near its posterior end. As one continues toward the plane of insertion, the fibers curve less and their lengths gradually decrease as they insert farther anteriorly along this plane. The fibers of the buccal half run ventromedial to meet those of the lingual half: the more posterior insert more posteriorly than the anterior fibers. The lengths of the fibers of the buccal half are equivalent to each other.

The ventrolateral portion of the MPl"T has a tendinous origin from the lateral and ventral aspect of the ectopterygoid-pterygoid process. 

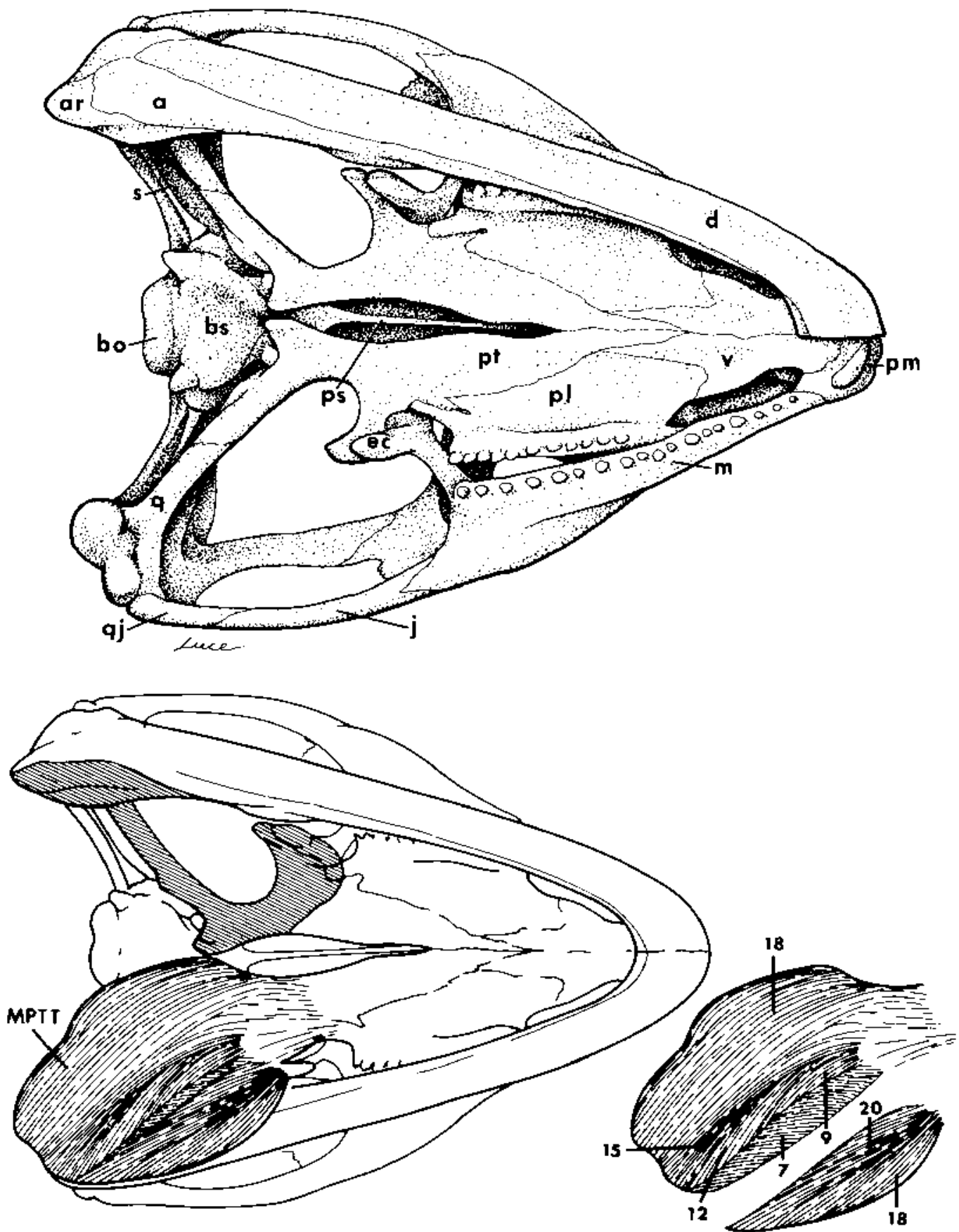

Fig. 3. Sphentodon punctatus. Tot: Ventral view of skult and right half of lower jaw. Note the close proximity of the coronoud process of the lower jaw and the pterygoid flange? and the arrangement of maxillary and palatine tooth rows. Bottom: Ventral view of the dissection after removal of the intermandibular and throat musculature. The cross-hatehed areas represent sites of atLachment of the MPTT. Ventral view of the middle: portion of the Mirl' with the ventrolateral portion displaced. Note the shape and fiber arrange. ment of the MPTT. The numbers give the lengths of the fibers (in mmin in the regions indicated. a, angular; bo, basioc. cipital; bs, basisphenoid: ec, ectopterygoid; M PTT, M. ptery. foideus typicus; ps. paraspheneid; s, stapes; v, vorner. Other abbreviations as in Figure 2 . 
Its fibers first pass ventrolaterally and slightly caudad to the ventral margin of the mandible; they then curve posterolaterally to run along the ventral margin up to the posterior third of the jaw, where they insert on its medial, ventral, and ventrolateral surfaces. The ventralmost fibers insert most posteriorly on the mandible and the medial and lateral $\mathrm{f} i$ bers anteriorly. The fiber lengths for the different regions of the middle and ventrolateral portions are shown in Figure 3.

\section{M. pterygoideus atypicus (МР'ГA; Figs. 1.2)}

The M. pterygoideus atypicus is the largest of the deep jaw muscles. It originates ventral to the eye on the dorsal surface of the palatine and can be exposed by elevating the eye and its loose connective tissues. The lateralmost fibers originate most anteriorly and the medial most most posteriorly. Its fibers pass caudad and slightly dorsolaterad, bridging the gap between the posterior end of the palatine and the pterygoid. From here they continue caudad. passing medially through a slightly rounded depression in the ectopterygoid-pterygoid process. After bending through about $80^{\circ}$, they continue posteroventrad to insert on the medial surface of the lower jaw, just ventral and posterior to the coronoid bone. The lateralmost fibers insert anteriorly and the medialmost posteriorly. The fiber lengths of the MPrA (16-17 mm) are relatively constant from its medial to lateral margins.

\section{Introduction}

\section{Feeding movements}

General terminology. A feeding sequence consists of prey capture. mastication, and swallowing. Mastication is subdivided into reducing, repositioning, and terminal phases. fach single swing of the mandible, starting with opening of the mouth and continuing through closing. is referred to as a cycle. Fach cycle is divided into phases defined by obvious changes in the movement pattern.

l'reliminary information about muscular activity is provided by the externally visible movements of the jaws and tongue and by the bulging muscles, specifically of the $\mathrm{Mm}$. adductor mandibulae externus medialis (dorsal temporal fossa) and superficialis (ventral temporal fossa) and the M. depressor mandibulae. The bulky tongue is highly mobile, plays an important role in capture and manipulation of food, and is visible whenever the mouth is open. Individual cycles of masticatory phases differ when the animals are reducing the food. when they are repositioning it between the jaws, and during the terminal phase, just prior to swallowing.

Reducing movements. Reducing movements usually comprise groups of two to four cycles during which the prey is positioned between the teeth on one side of the head. In each cycle, the mouth first opens slowly and then continues to open more rapidily until maximum gape for the cycle is reached. It next closes rapidly and then slows down as the food is contacted. During slow closing. the mandible first continues to move upward and then moves anteriorly. The mouth then opens slightly and the mandible remains immobile until the start of the next cycle. During these reduction cycles, strain gauges placed at right angles to the tooth row generate a doublepeaked output (see below).

Changes in the size of the prey do not produce fundamental changes in mandibular movement. However, the horizontal and verlical excursions of the head are greatest when large prey is being reduced. Also the duration of certain phases of the masticatory cycle then increases.

Repositioning movements. Food is shifted posterolaterad during the individual chewing cycles of a group. Subsequently, it is repositioned between the tooth rows of the same or the opposite side. $\Lambda$ t the start of a repositioning movement, the mouth opens farther than during reducing movements. The tongue shifts the food as the mouth opens and displaces it anteriorly and laterally. Reposition. ing movements produce single peaks of greater amplitude and duration than chewing cycles on the strain gauge records. Occasionally, the food may be repositioned without a significant change in the pattern of chewing movements.

Terminal movement. At the very end of a reduction sequence, the tongue moves the food towards the back of the oral cavity. In such ter. minal movements, the mouth opens slightly wider and longer than it does during chewing cycles. Strain gauge records show a single peak of relatively long duration.

\section{Feeding on crickets and cockroaches}

Capture. Tuataras respond to moving prey by cocking their head towards it. While they ordinarily ignore motionless prey. they may ingest it after it has been moved around with tweezers.

When a (hungry) tuatara notices insects moving on the ground, it points its head towards the prey, opens the mouth, and then 
everts the tongue. 'The tongue first lifts slightly out of the buccal floor and then begins to protrude; during this movement its dorsal surface remains straight and the tongue appears thin in profile (Fig. $4 \mathrm{~B}$ ). As the tongue protrudes beyond the symphysis, its upper surface curves. The middle of the tongue then seems to be pushed upward and forward, but the anterior portion appears to be fixed to the symphysial region so that the tongue starts to double back under itself (Fig. 4C). The head continues to move towards the prey and cineradiographs show that the hyoid isupporting the trachea and posterior lingual portion) is protracted. 'This protraction of the hyoid moves the posterior aspect of the tongue towards the symphysis.

During capture, the sticky dorsal surface of the anterior portion of the tongue rotates around the symphysis to lie ventrally. The ventrally directed surface is pushed against the food (Fig. 4D) by a combination of tongue eversion and the forward and downward move. ment of the head (Fig. 4E). I Iyoid, tongue, and adherent prey are then withdrawn into the oral cavity (Fig. $4 \mathrm{~F}$ ) and the mouth closes.

Reducing movements. Retraction of the tongue pulls the adherent prey into the mouth, where it generally comes to resi partially across one set of tooth rows; two to three preliminary masticatory or immobilizing cycles follow. The tongue then repositions the cricket posteriorly near the corner of the mouth and between either set of teeth, after which mastication proper begins. The cricket generally remains in a fixed position relative to the upper jaw for two to four masticatory cycles. Occasionally, propalineal shearing movements of the lower jaws shift the cricket slightly anteriad. The cricket is then repositioned by the tongue either to the same or the opposite side as the mouth opens: two to three more masticatory cycles follow. Such groups of cycles occur repeatedly during a reduction sequence. Increasing amounts of secretion become visible around the cricket and it becomes reduced to a saliva-covered, mushy mass after approximately 15 chewing cycles.

A masticatory cycle (Figs. 5, 6) may be subdivided into six phases: 1) slow-opening, 2) fast opening, 3) fast-closing, 4) crushing, 5) shearing, and 61 resting; all are best described from lateral views (Fig. 5!.

During the slow opening phase (1), the lower jaw first rotates open slowly. Cineradiographs show that the retroarticular process of the mandible simply rotates about a transverse axis through the quadrate. During the fast. opening phase (2), the lower jaw rotates open more rapidly; but the entire jaw also moves posteriorly. Cineradiographs show that the retroarticular process of the mandible continues to rotate. but simultaneously translates posteriorly along the articular surface of the quadrate. The fast opening phase ends with the moulh wide open and with the retroarticular process shifted posteriorly in the man. dibular fossa,

During the fast-closing phase $(3\}$, the mandible first rotates closed rapidly and only decelerates when the teeth contact the food. The anterior shift of the mandibular tip at the end of fast closing is so minor that the articular process shows no obvious translation in cineradiographs. Next follows the distinct crushing phase (4). The dorsal and lateral adductor masses on the working side of the head bulge obviously and one may hear chitin being fractured. During the crushing phase, the mandible slowly rotates toward closure; it also moves slightly forward as the retroarticular process both rotates about the quadrate and translates anteriorly. During the shearing phase (5), the mandible obviously moves anteriorly; food held fixed against the maxillary and palatine tooth rows is sheared by the mandibular row acting like a saw. Large food items tend to be rotated slightly and the skin of the mouth adjacent to the food is pulled taut during this propalineal (anteriad) shift. The shearing phase lasts until the mandible drops slightly and moves slightly posteriorly, sepa. rating the upper and lower teeth. During the resting phase (6), the lower jaw remains slight. ly depressed until the start of the slow opening phase of the next cycle.

During the crushing phase, the muscles bulge noticeably out of the dorsal temporal fossa. Normally the food is asymmetrically positioned; the muscles of the working side then bulge slightly earlier and more obviously than do those on the balancing side. During the fastclosing and crushing phases, muscles on the working side also bulge slightly out of the ventral temporal fossa. Muscles of the anterior portion of the ventral fossa begin to buige during fast closing; those of the posterior portion bulge next, during the crushing phase.

Records from the strain gauge (Fig. 6) crossing the gape reflect the jaw movements during a chewing cycle as a double-peaked curve; the first peak is larger than the second. The rise of the first peak correlates with the start of fast opening, the peak indicates the transition from 

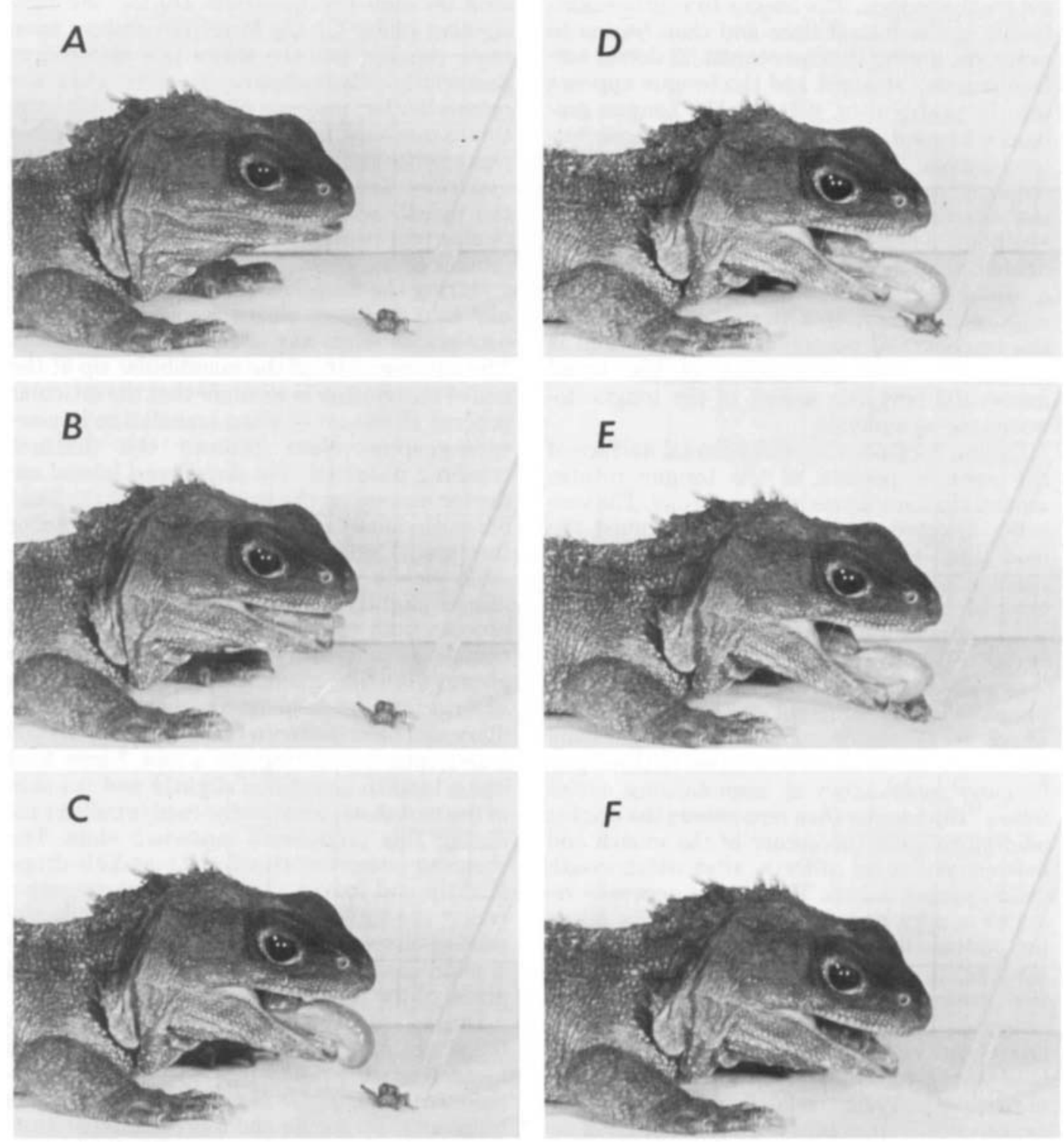

fijg. 4. Siphesudun punctatus capluring a crickel. Suc(2essivet trames (24 framesisec.l from a 16 -tnm. strobe-ex. posed filn. An immobilized (chilled) cricket was

fast opening to fast closing, and the signal returns to base line at the end of the fast closing phase. The small secondary peak is produced by the bulging of the dorsal adductor mass and consequently correlates with the crushing phase. The relative height of this secondary peak is higher on the working than on the balancing side. No strain gauge dis-

manipulated by a plastic rod to attract the tuatara and elictit ferding within a corcunseribed area. This procedure was used in most recording sescions.

placements occur during the slow opening and shearing phases, nor do the strain gauges indicate anteroposterior movements and the relative opening of the mouth during the resting phase.

In general, the length of all phases, except for the resting one, decreases as does the excursion of the jaws throughout a reduction se- 


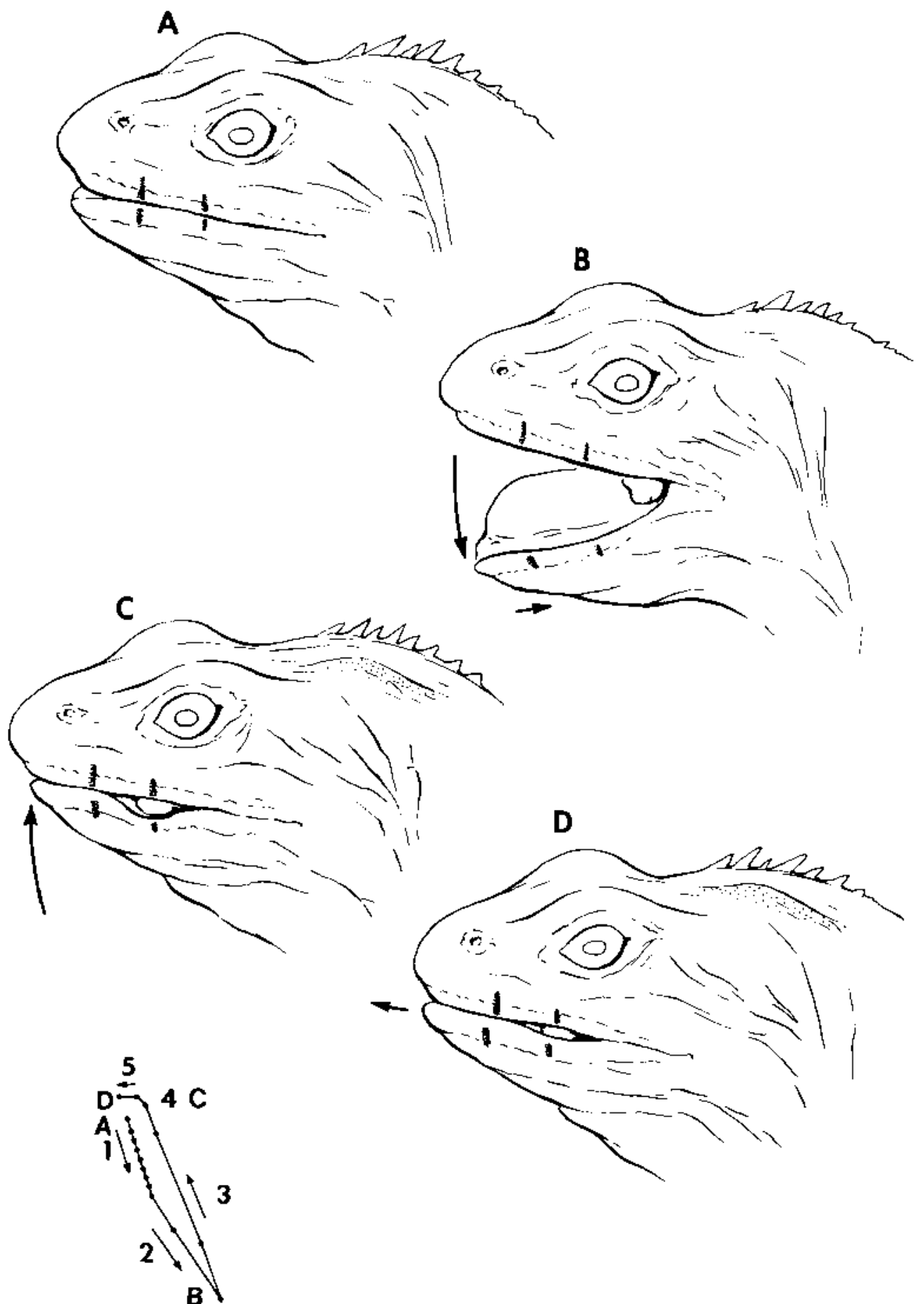

Fig. 5. Sphenodon punctatus. Displacenent of lower jaw during a chewing cycle traced from $16 \cdot \mathrm{m} n$ movie. Arrows indicate the movetnent of the jaw bet ween frames as food is ruduced between the left tooth ruws. The vertical bars crossing the labial zone are panted reference markers indicuting the extent of the propalineal shift. 'The stippled area

represents the bulging of the working side adductors during crushing and shearing phases. The insert shows the path of the tip of the mandible relative to the head during a reducing cycle. 1, slow-epenitı phase; 2 . tast-opening phase; 3 , fast. closing phase: 4 , crushing phase: $\overline{5}$, shearing phase. 

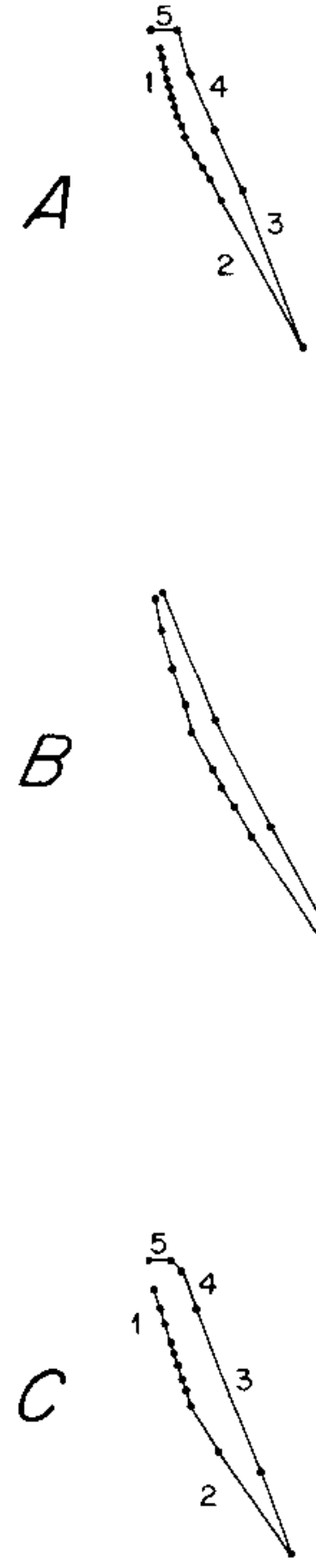
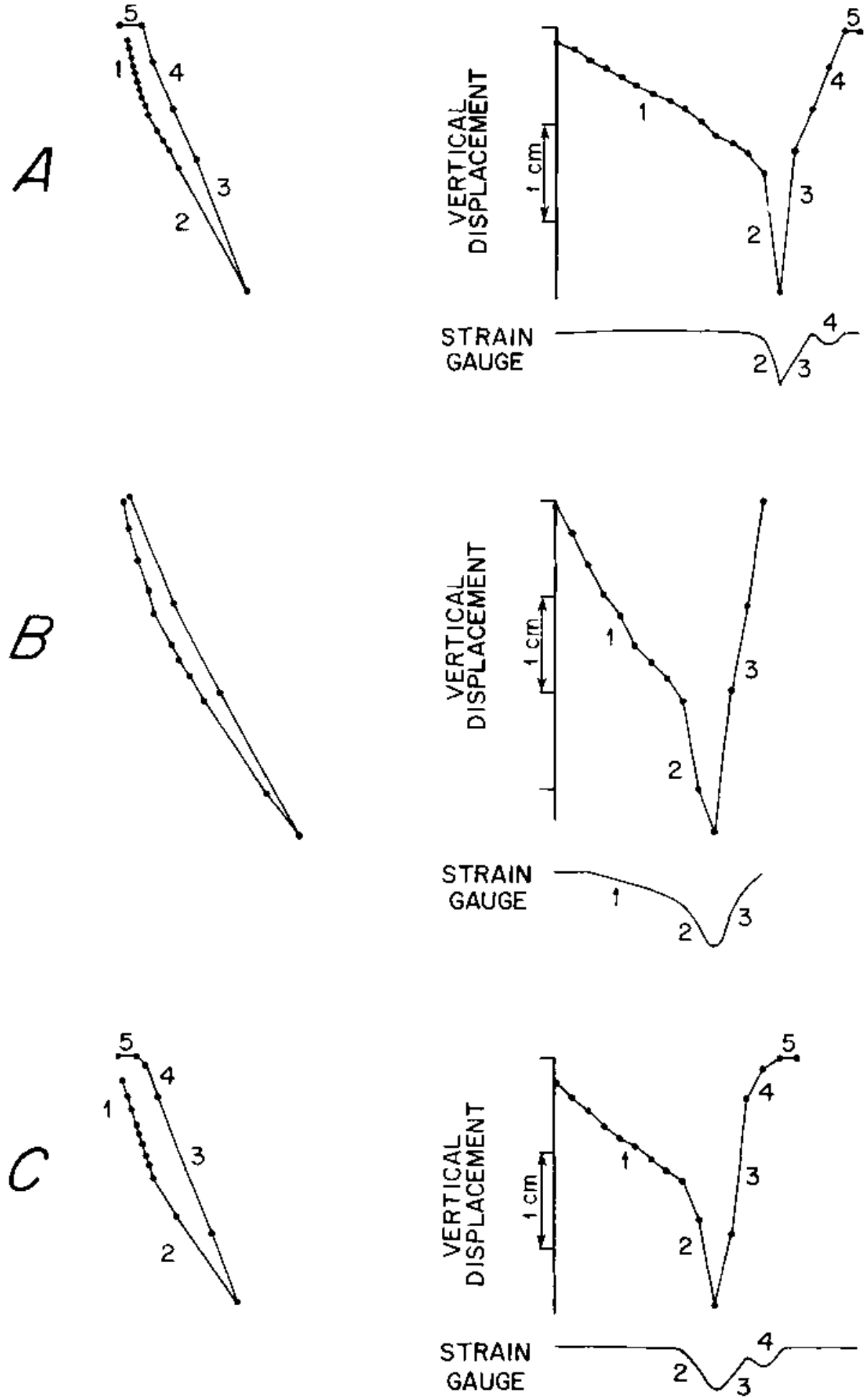

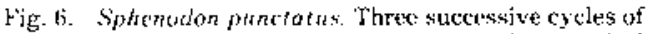
the left tip ol the jaw (left) and their currosponding vertical displactment graph and stram gatuge record irights when a tuatara d'educes a cricket $A$ : 'The working side is on the left.
B: Food is rtpositioned to the right. C: The balancing side is on the left. The uumbers accompanying the crcles, displacement graphs, and strain gauge records indicate fove of the six phase's of a reduction cycle. 
quence. Neither direct observations nor anahysis of films suggests that the mandible moves laterally, or that the lower jaws rotate about their long axes.

The lower jaws reach maximum opening velocity during the initial one-third of the fast opening phase (Fig. 7). The velocity then smoothly reverses to a maximum closing value that occurs during the first one-third of the fast-closing phase. Maximum closing velocities tend to be greater than or equal to (rarely less than) maximum opening velocities. Maximum opening acceleration of the lower jaws occurs at the start of fast opening and the two-to three-times greater maximum closing accelera. tion is reached at the start of the fast closing phase.

Repositioning movements. Insects are repositioned every three to five cycles. Repositioning cycles occur about $100 \mathrm{msec}$. after the end of the shearing phase of the previous reduction cycle; the resting phase before a repositioning cycle is only $40 \%$ as long as that between two reduction cycles.

As the mouth begins to open, the tongue twists towards the working side to contact and slide the cricket off the double tooth rows. The mouth opens wider than during a chewing cy. cle and the tongue arches dorsally, first centering the cricket in the oral cavity and, as the mouth closes, repositioning it laterally for the first cycle of the next chewing sequence.

As the mandible reaches a wide open position during repositioning. the skin covering the dorsal temporal fossa sinks inward slightly but then rises and straightens during the fastclosing phase. Strain gauge records do not show a secondary peak.

Terminal movements. As the cricket becomes crushed, it is gradually worked posteriorly to the central region of the oral cavity; reduction cycles then pass smoothly into terminal ones.

Terminal movements are characterized by dorsal and anterior arching of the tongue which usually rubs against the roof of the mouth (and collects food from it). During this movement the lingual tip extends beyond the anterior margin of the maxillary tooth row. The tongue (and hyoid) then retract, carrying the food into the buccal cavity. The mouth opens slightly wider and for a longer interval during terminal cycles than during masticatory cycles.

The dorsal adductor musculature does not bulge obviously (so the strain gauge records do not show a secondary peak). Furthermore, there is less propalineal displacement of the mandible during terminal cycles than during masticatory ones; the path of the mandibular tip shows only a slight anteroposterior displacement when the mouth opens and closes. During the fast opening phase, the mandible and its articular process show only a slight posterior translation and during the crushing and shearing phases only slight anterior translation. There are usually five terminal cycles at the end of a reduction sequence.

Mandibular displacement during terminal cycles is similar to that during reducing ones. Maximum opening velocity occurs during the last one-third of jaw opening, and maximum closing velocity takes place during the first one-third of closing. Maximum opening acceler ation coincides with the start of fast opening and the two-times-greater maximum closing acceieration coincides with the start of fast closing.

\section{Feeding on mice}

General. Sphenodon ingests newly born mice in the same way that it does crickets and roaches. Portions of the feeding pattern change during ingestion of juvenile mice. Tables 2 and 3 show changes in reducing movements among reduction sequences for crickets, roaches, and juvenile mice.

Capture and immobilization. Sphenodon captures mice by biting them and obtaining a secure grip with the anterior teeth. The tongue plays no role during capture nor is it protruded. After capture, mice are shifted gradually deeper into the mouth by inertial movements of the head. These involve a rapid drop of the mandible with a simultaneous upward and forward movement of the head relative to the prey. The mouth then snaps closed and the head again moves downward. Captured mice are generally positioned transversely in the mouth across the tooth rows of both sides.

Coincident with or following the capture and posterior shift, Sphenodon makes a series of crushing bites that kill the mouse. The tooth rows on both sides are used simultaneously and the prey is not repositioned as long as it remains centrally located in the mouth. Repositioning occurs by rapid lateral movements of the head (with a simultaneous opening cycle) and effectively shifts the prey to the side opposite to that towards which the head moves. Both during capture and during inertial movements Sphenodon rotates its skull slightly dorsad around the head joint; this occurs coincjdent with mandibular depression. 


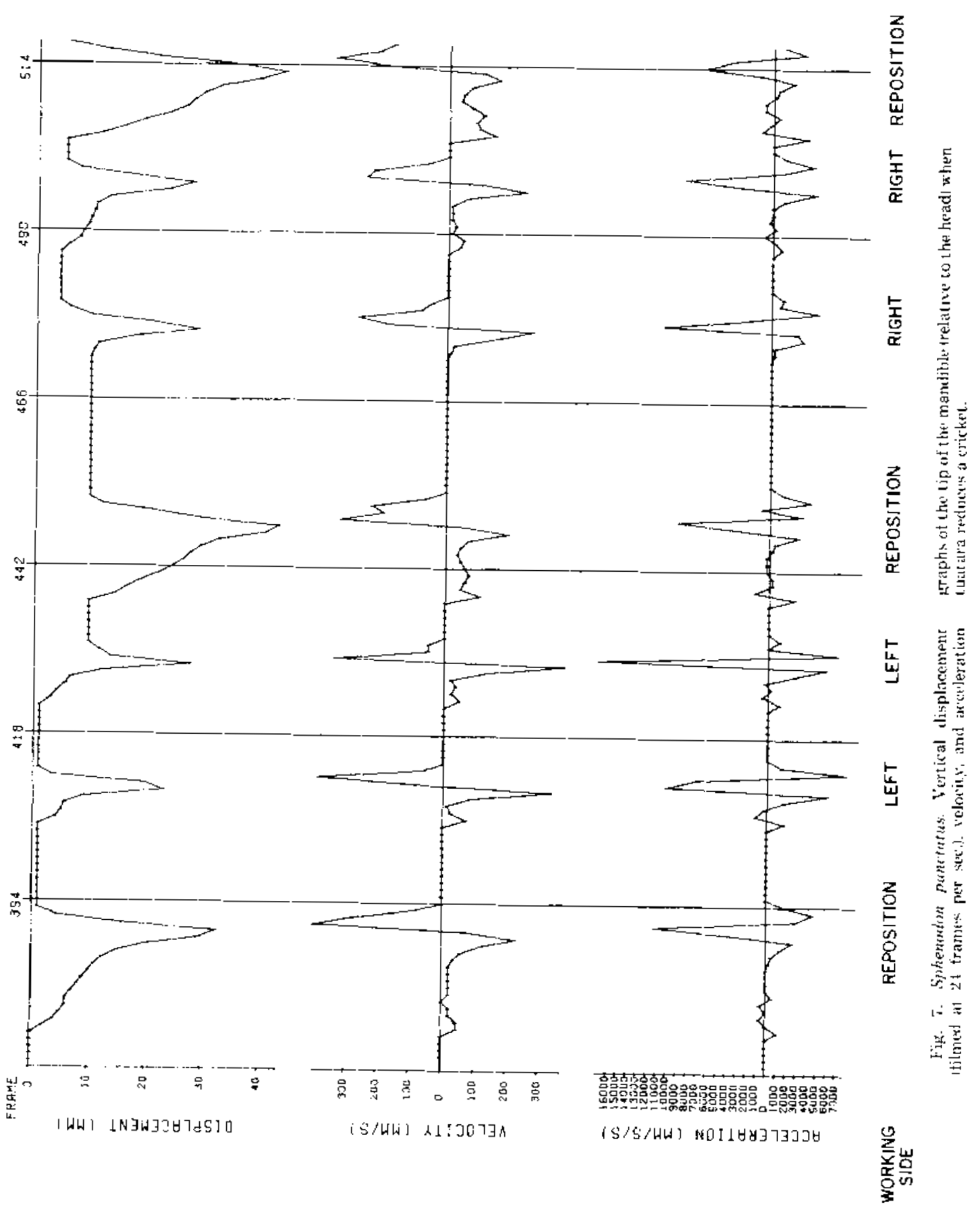


TABLE 2. Comparison of masticatory cycles uhen Sphenodon chew crickets, cock roaches, and jutenile mice

\begin{tabular}{|c|c|c|c|c|c|}
\hline Food & $\begin{array}{l}\text { Biles per } \\
\text { second }\end{array}$ & $\begin{array}{l}\text { Total number } \\
\text { of bites per } \\
\text { sequence }\end{array}$ & $\begin{array}{l}\text { Duration } \\
\text { of bite } e^{2}\end{array}$ & $\begin{array}{l}\text { Duration of } \\
\text { repositioning } \\
\text { movements }{ }^{2}\end{array}$ & $\begin{array}{l}\text { Duration of } \\
\text { termina! } \\
\text { movements }\end{array}$ \\
\hline Crickets & $\begin{array}{c}0.84 \pm 0.13 \\
(\mathrm{~N}=190)\end{array}$ & $\begin{array}{c}21.2 \pm 3.39 \\
(N=12)\end{array}$ & $\begin{array}{c}502.6 \pm 80.4 \\
\{\mathrm{~N}=50\}\end{array}$ & $\begin{array}{c}709.3 \pm 98.4 \\
(\mathrm{~N}=23)\end{array}$ & $\begin{array}{c}891.7 \pm 305.5 \\
(\mathrm{~N}=16)\end{array}$ \\
\hline Cockroaches & $\begin{array}{c}0.83 \pm 0.87 \\
\{N=130\}\end{array}$ & $\begin{array}{c}32.0 \pm 5.63 \\
\{\mathrm{~N}=9\}\end{array}$ & $\begin{array}{c}620.7 \pm 140.6 \\
(N=50)\end{array}$ & $\begin{array}{c}831.9 \pm 151.3 \\
(N=31)\end{array}$ & $\begin{array}{c}1072.2 \pm 180.4 \\
(N=20)\end{array}$ \\
\hline $\begin{array}{l}\text { Juvenile } \\
\text { mice }\end{array}$ & $\begin{array}{c}0.55 \pm 0.06 \\
|\hat{x}=192|\end{array}$ & $\begin{array}{c}38.4 \pm 4.82 \\
(\mathrm{~N}=51\end{array}$ & $\begin{array}{c}877.4 \pm 187.4 \\
(N=42)\end{array}$ & $\begin{array}{c}1394.1 \pm 237,4 \\
(\mathrm{~N}=15\}\end{array}$ & $\begin{array}{c}1300.5 \pm 398.9 \\
\mid \mathrm{N}=11\}\end{array}$ \\
\hline
\end{tabular}

'Bites are defined us the start of slow: opening to the start of the resting phase. Data are mean \pm SD.

'Miljeconds.

TABLE 3. Duration (msec.) of the six phasts of masticatory cycles when Sphenodon chetu crickets, cockroaches, and juvenile mice

\begin{tabular}{|c|c|c|c|c|c|c|c|}
\hline Ford & $N$ & $\begin{array}{l}\text { Slow- } \\
\text { opening }\end{array}$ & $\begin{array}{c}\text { Fast- } \\
\text { opening }\end{array}$ & $\begin{array}{l}\text { Fast- } \\
\text { closing }\end{array}$ & Crushing & Shearing & Resting \\
\hline Crickets & 10 & $\begin{array}{c}141,04 \pm 29.5 \\
\mid 21 \% 1 \% 1\end{array}$ & $\begin{array}{c}95.53 \pm 20.5 \\
114 \%\}\end{array}$ & $\begin{array}{c}82.00 \pm 20.5 \\
\{12 \%\}\end{array}$ & $\begin{array}{c}68.06 \pm 20.5 \\
\left(10^{\circ} .\right)\end{array}$ & $\begin{array}{c}63.55 \pm 21.6 \\
(9 \%)\end{array}$ & $\begin{array}{c}232.06 \pm 1140) \\
\left(34^{\circ}\right)\end{array}$ \\
\hline Cockroaches & 10 & ${ }_{(21)}^{145.55 \pm} 41.4$ & $\begin{array}{c}86.51 \pm 13.5 \\
\{12 \%\}\end{array}$ & $\begin{array}{c}77.08 \pm 13.5 \\
111 \% 1\end{array}$ & $\begin{array}{c}63.96 \pm 21.3 \\
(9 \%)\end{array}$ & $\begin{array}{c}63.55 \pm 21.6 \\
\mid 946)\end{array}$ & $\begin{array}{c}264.04 \pm 134.5 \\
\left\{38 \omega_{0}\right\}\end{array}$ \\
\hline $\begin{array}{l}\text { Juvenile } \\
\text { mice }\end{array}$ & 10 & $\begin{array}{c}414.51 \pm 116.4 \\
(25 \%)\end{array}$ & $\begin{array}{c}132.02 \pm 18.0 \\
(8 \%)\end{array}$ & $\begin{array}{c}113.57 \pm 18.0 \\
(7 \%)\end{array}$ & $\begin{array}{c}86.51 \pm 13.5 \\
\{5 \%\}\end{array}$ & $\begin{array}{c}91.02 \pm 27.1 \\
(5 \%)\end{array}$ & $\begin{array}{c}843.37 \pm 203.4 \\
\{50 \%\}\end{array}$ \\
\hline
\end{tabular}

'Number in parenthesis durecily below each tnean equads the duration in percentage of the entire cycle $\mathbb{N}$ expurls number of

Reducing movements. At the start of reduction, the mice are shifted inertially to one side of the mouth by rapid mouth opening with coincident lateral shifts of the head. Simultaneously, mice tend to be shifted posteriorly as the head moves forward relative to the prey. 'The mice are repositioned inertially after each set of four to seven cycles. The tongue is not noticeably involved in the manipulation of large prey during these early stages of mastication.

As reduction of mice proceeds, movements of the mandible resemble those during the reduction of crickets. However, reduction of mice differs by upward movements of the entire head as the mouth opens, and downward movements as it closes; the head also tilts tow ards the balancing side during the first half of a reduction sequence. Thereafter, head movements cease, only the lower jaw cycles, and the tongue becomes involved in the manipulation of the food. During terminal cycles, the tongue protrudes but does not arc upward as it does during the reduction of crickets; nor does it appear to rub against the roof of the mouth.

Portions of mice may remain outside of the mouth during most of the reduction sequence.
Protruding limbs and even the heads of mice will then be cut off, but the severed portions are not picked up and only the part in the mouth is ingested. This observation may explain the comments that decapitated petrels were found in areas inhabited by tuataras (Crook, 75).

\section{Electromyography - Capture}

As the mouth starts to open, the anterior and posterior portions of the $M$. depressor mandibulae (MDM) begin to fire bilaterally. The anterior portion first reaches its maximum level and continues at this level until the mouth is almost completely open. However, the posterior portion first reaches a $25-30 \%$ level, becomes more active to a 50-60\% level, and then reaches its maximum level near the end of opening. As the mouth reaches a wideopen position, the anterior portion of the M. adductor mandibulae externus superficialis (MAMES) starts to fire at a 20-25\% level. Both portions of the MDM first become less active and then silent as the mouth starts to close.

Closing of the mouth is accompanied by increased activity in the anterior portion of the 
MAMES and by the start of activity in the posterior portion of the MAMES, the anteromedial and posterior portions of the $M$. adductor mandibulae externus medialis, the M. pseudotemporalis superficialis, as well as the superficial and deep parts of the middle portion of the M. pterygoideus typicus. All of these adductors become more active during closing and attain maximum activity when the teeth contact and then crush (or penetrate) the prey. Thereafter, the adductors become less active as the mouth is closed and then silent as it opens slightly and stops moving. All of these adductors, as well as the MDM, remain silent as the mouth stays motionless, even though crickets and cockroaches lie partially across one set of lower teeth and juvenile mice across both sets.

\section{Electromyography - Reduction}

$M$. depressor mandibulae (MDM). The $\mathrm{M}$. depressor mandibulae of the working and balancing sides are active bilaterally and symmetrically during the opening phase of a reduction cycle. However, the pattern of activity differs between the anterior and posterior portions of this muscle. Maximum voltages are $1.84 \mathrm{mV}$ for the anterior and $2.32 \mathrm{mV}$ for the posterior portion.

The anterior portion of the MDM starts to fire at a $10 \cdot 15 \%$ level at the beginning of the slow-opening phase and continues to fire at this level throughout this phase; the posterior portion remains silent. $\Lambda t$ the start of the fastopening phase, activity of the anterior portion reaches $40-60 \%$, increases to $80-100 \%$ about midway through the fast-opening phase, and then drops to $20-30 \%$ as the lower jaw reaches its furthest ventral excursion (Fig. 8). The posterior portion of the MDM becomes active at a $40-60 \%$ level and maintains this level throughout fast opening. Both portions of the MDM become silent once the mouth reaches the wide-open position and remain inactive during the fast-closing, crushing, shearing. and resting phases.

Activity of both the anterior and posterior portions of the MDM is greater at the start than at the end of a reduction sequence and least during terminal cycles. When food is repositioned, the start and cutoff of activity in both the anterior and posterior portions are similar to those seen during a reduction cycle. However, the level of activity of the posterior portion reaches $100 \%$ during the repositioning movements, which is more than $40 \%$ greater than its maximum activity level during reduction cycles.
M. adductor mandibulae externus superficialis sensu stricto (MAMES). The anterior and posterior portions of the MAMFS are active asymmetrically during reduction cycles and the level of activity is greater for the muscle on the working than on the balancing side. Maximum voltage is $0.86 \mathrm{mV}$ for the anterior portion and $2.28 \mathrm{mV}$ for the posterior one.

As the mouth starts to close, the anterior portion of the MAMES of the working side begins to fire at a 20-30\% level (Fig. 8). Activity increases during closing to reach levels of $90-100 \%$ on the working side and $40-60 \%$ on the balancing side during the crushing phase. Activity of the MAMES of the working side then drops to $0-30 \%$ as the lower jaw starts to move anteriorly during the shearing phase. However, the posterior portion of the MAMES is silent until the start of the crushing phase. The level of activity then builds rapidly to $70-100 \%$ on the working side and then decreases sharply to below $40 \%$ as the crushing phase ends. The posterior portion of the muscie is generally silent during the shearing phase. Both portions of the MAMES are silent during the resting and opening phases of a reduction cycle.

During repositioning cycles, the anterior portion of the MAMES starts to become active at a $10-20 \%$ level at the end of the fast-opening phase and throughout the fast-closing phase. Unless the repositioning cycle has placed food between the tooth rows, the activity remains at $20-50 \%$ during the next crushing phase. When food has been positioned between the teeth, the MAMES becomes more active, reaching 70-100\% during the crushing phase.

$M$. adductor mandibulae externus medialis (MAMEM). The anteromedial (-b-), posterior $(-\mathrm{c}-\}$, and ventrolateral $\{-\mathrm{a}-\}$ heads of the $\mathrm{M}$. adductor mandibulae externus medialis are bilaterally and asymmetrically active during a reduction cycle, and the level of activity is greater for the head on the working side than for that on the balancing one. Activity decreases as the food is reduced, as it is repositioned, and during terminal cycles. Maximum voltage is $1.74 \mathrm{mV}$ for the anteromedial, 2.48 $\mathrm{mV}$ for the posterior, and $1.94 \mathrm{mV}$ for the ventrolateral head.

All heads of the MAMEM of the working and balancing sides are silent at the start of closing; those of the balancing side remain silent throughout the fast-closing phase. However, as the teeth approach the food late in the fast-closing phase, all three portions of the working side start to fire at a $20-30 \%$ level (Fig. 81. Their activity increases rapidly at the 

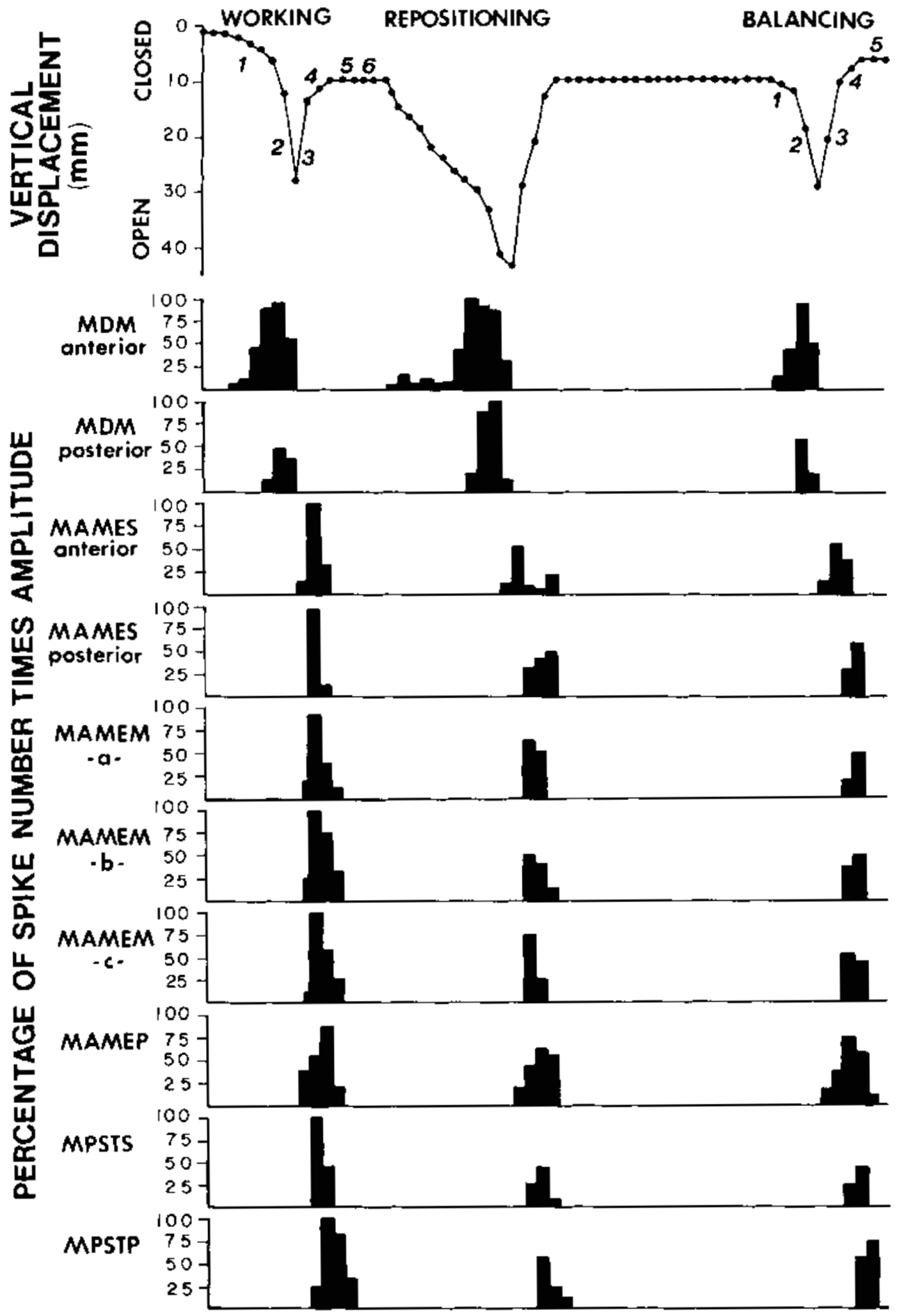

TIME

Fin. R. Sphenuten punctatus. Synthetic summary ol a sequence of vert ical stisplacements of the lower jaw and bar nraphs of the percentage ol the number of FMli spikes times the mean spike amplitude when a tuatara reduces a cricket. Nluscle abbreviations as in Figure 1. The numbers (I a reduction cycle 
start of the crushing phase, reaching 70-100\%, Activity of the posterior and ventrolateral heads then drops to a $40-60 \%$ level and the anteromedial one to a $50-70 \%$ level as this phase ends. The posterior and ventrolateral portions of the MAMEM of the working side show a $10-20 \%$ level of activity at the start of the shearing phase, whereas the anteromedial portion shows a 20-40\% level. The three heads then become silent and remain so through the resting phase. Activity of the anteromedial and ventrolateral portions of the balancing side builds to a $30-40 \%$ level at the start of the crushing phase, increases to $50-60 \%$, and then drops to $0-10 \%$ as the crushing phase ends; activity of the posterior head first increases rapidly to $50-60 \%$ and then drops to a $30-40 \%$ level. They become silent at the start of the shearing phase and remain so throughout the resting and opening phases.

$M$, adductor mandibulae externus profundus (MAMEP). The $\mathrm{M}$. adductor mandibulae $\mathrm{ex}$ ternus profundus is bilaterally active during a reduction sequence. Activity is greater on the working side than on the balancing one and decreases on both sides as the food becomes reduced. Maximum voltage is $1.28 \mathrm{mV}$.

The muscles on both sides start to fire at a 20-40\% level at the start of fast closing (Fig. 8 . Activity increases to $50-60 \%$ and reaches $90-100 \%$ on the working and $60-80 \%$ on the balancing side during the last half of the crushing phase. Thereafter, activity decreases bilaterally to a $0-30 \%$ level during the first half of the shearing phase. Both muscles are silent during the resting phase.

$M$. pseudotemporalis superficialis (MPSTS). The M. pseudotemporalis superficialis of the working side is more active than the MPSTS of the balancing side, which shows variable activity during reduction cycles. Both sides also show variable and low levels of ac tivity during terminal cycles. Maximum voltage is $1.72 \mathrm{mV}$.

The MPSTS of both the working and balancing sides are silent at the start of closing and during the fast-closing phase of reduction cycles. The MPSTS of the working side becomes active at the start of the crushing phase. Activity increases rapidly to $80-100 \%$ and then drops quickly to below $50 \%$, to end at the start of the shearing phase (Fig. 8). Simultaneously, the MPSTS of the balancing side is active at a $20-40 \%$ level. Both sides are silent throughout the shearing, resting, and opening phases.

$M$. pseudotemporalis profundus
(MPSTP). The M. pseudotemporalis profundus of the working side is more active than that on the balancing side. Maximum voltage is $0.71 \mathrm{mV}$.

The MPSTP of the working side begins to fire at the start of the crushing phase. Activity increases rapidly to reach $75-100 \%$ at the start of the shearing phase but then decreases rapid ly to $20-30 \%$ at the end of shearing. The MPSTP of the balancing side fires later and is active for a shorter period than the muscle of the working side. Activity of the balancing side MPSTP begins at the end of the crushing phase and increases rapidly to a $60-80 \%$ level early during the shearing phase; it rapidly drops to zero near the end of shearing. The MPSTP of both the working and balancing sides are inactive during the resting and opening phases.

M. pterygoideas typicus (MPTT). Both the superficial and deep medial parts of the middle portion of the $M$. pterygoideus typicus of the working and balancing sides are active asym. metrically. The level of activity of both parts is greater for the working than for the balancing side and activity decreases as the food is reduced. Maximum voltage is $1.86 \mathrm{mV}$ for the superficial medial part, $1.90 \mathrm{mV}$ for the superficial deep part, $1.46 \mathrm{mV}$ for the superficial lateral part, $1.54 \mathrm{mV}$ for the deep lateral part, and $1.30 \mathrm{mV}$ for the ventrolateral part.

The superficial medial part of the middle portion of the MPTT of the working side begins to fire at a $10-30 \%$ level during the fast-closing phase (Fig. 9). Activity increases during the crushing phase to reach $70-100 \%$ at the start of the shearing phase, then decreases rapidly to $10-25 \%$ at the end of this phase, and ceases at the start of the resting phase. The deep medial part of the MPTT of the working side begins to fire later than the superficial one, oniy starting to show a $20-40 \%$ level of activity during the crushing phase. Activity increases throughout the crushing phase and reaches $70-100 \%$ at the start of the shearing phase. The deep part rapidly becomes less active to $10-30 \%$ and is silent throughout the resting phase.

The superficial medial part of the middle por. tion of the MPTT of the balancing side shows an activity pattern similar to but of lower amplitude than that of the working side. However, the deep part of the MPTT of the balancing side is active later than that of the working side. For the deep part of the balancing side, activity starts during the last half of the crushing phase and then increases rapidly to 
reach $40-60 \%$ at the start of the shearing phase. Activity then decreases rapidly and ceases at the start of the resting phase.

The superficial and deep lateral parts of the middle portion of the MPTT of the working side fire asymmetrically (Fig. 9). The superficial lateral part begins to fire at a $10-40 \%$ level at the start of the crushing phase. Activity then increases during the first part of the shearing phase, reaches $80-100 \%$ near the end of shearing, and decreases rapidly thereafter. The deep lateral part of the working side is active at a $10-30 \%$ level during the fast-closing phase, remains so during crushing, increases to $70-100 \%$ during the shearing phase, but then decreases rapidly to a $0-20 \%$ level.

The superficial lateral part of the balancing side begins to fire at the start of shearing. Activity first increases rapidly to $20-30 \%$ and then decreases rapidly at the end of shearing. The deep lateral part of the balancing side shows an activity pattern similar to the working side but at a lower level. Both the superficial and deep lateral parts of the working and balancing side are silent during the resting and opening phases.

The ventrolateral portion of the MPTT' is active throughout most of a masticatory cycie but at varying activity levels. The ventrolateral portions of the working and balancing sides show similar activity patterns; however, the activity levels of the working side muscle are greater than those of the balancing side.

The ventrolateral portion of the working side shows two bursts of activity as the mouth closes and variable low level activity during the resting phase. The first burst of activity begins at the start of fast closing. Activity increases rapidly to $40-60 \%$. but then decreases rapidly to $0-20 \%$ during crushing. This decreased level is followed by a second burst during which the activity level reaches maximum at the start of the shearing phase. Activity then decreases to $10-20 \%$ as the shearing phase ends. The ventrolateral portions remain active at a level varying between zero and $25 \%$ during the resting phase.

During terminal cycles, the activity pattern of the medial and lateral parts of the middle portion of the MPTT, as well as the ventrolateral portion differ from that during chew. ing (Fig. 9). The deep medial part starts to fire at a $5-20 \%$ level at the start of the shearing phase and continues throughout the resting phase at a $20-50 \%$ level and into the start of slow opening at a $5-20 \%$ level. In contrast, the superficial medial and lateral parts and the deep lateral part and the ventrolateral portion of the MPTT now are silent during closing of the mouth and active when it opens. The superficial medial and lateral parts become active at a $10-25 \%$ level at the end of the resting phase, continue through slow and fast opening at a $20-60 \%$ level, and end as the mouth starts to close. The deep lateral part and the ventrolateral portion become active at the start of the resting phase and remain so through slow opening.

M. pterygoideus atypicus (MPTA). The M. pterygoideus atypicus of the working and balancing sides are active during the fastclosing, crushing, and shearing phases of a reduction cycle. However, the activity level of the working side MPTA is greater than that of the balancing side MPTA. Maximum voltage is $1.06 \mathrm{mV}$.

The MPTA of the working side begins to fire at a $20-30 \%$ level during the fast closing (Fig. 9). Activity then increases to $50-75 \%$ during the first part of the crushing phase and then reaches maximum near the end of crushing and the start of the shearing phase. During shearing, the activity level remains high $(60-75 \%)$ but then decreases rapidly as the shearing phase ends. Activity of the MP'TA of the balancing side initiaily reaches a $15-20 \%$ level during fast closing. Activity then increases slightly to $30-40 \%$ during crushing and re mains so during the first part of the shearing phase; it then drops to zero as shearing ends. Both the MPTA of the working and balancing side are inactive during the resting and opening phases and during terminal cycles.

\section{General}

\section{DISCUSSION Masticatory pattern}

The dentition of Sphenodon is functionally heterodont. As already noted (Robinson, '76), the large anterior (successional) marginal teeth are analogous to canines. As none of the acrodont teeth are replaced and new teeth deveiop at the rear of the series, the tooth series retains a sequence of teeth that show size increases from front to rear.

However, the size increase is uneven; thus Robinson's reference ('76) to "successional," "remnant hatchling," and "additional" dental regions. As earlier stated by Günther (1867), old individuals still retain the small remnant hatchling teeth anteriorly; as these teeth become smaller, wear marks gradually develop on the dentary itself (Robinson, '76). The wear 

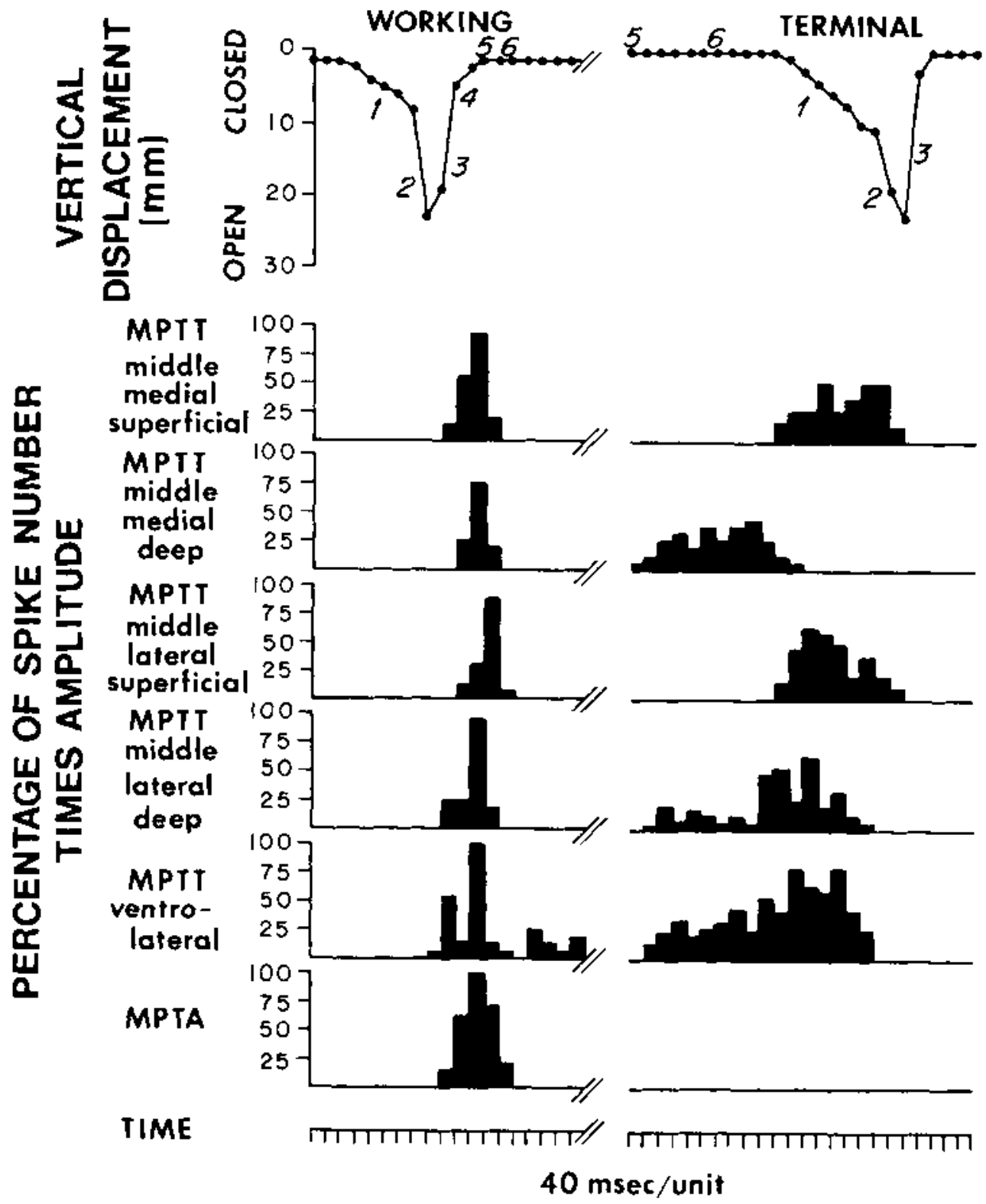

Figt. 9. Sphtnorten pumctostus. Sy nthet ic summary of the percentane of the number of EMG spike's times the mean spike amplitude of the difterent portions of the $\mathbf{~} 1$.

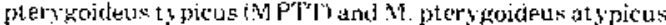
(N) $\mathrm{J}^{2} \mathrm{~A}$ or the working side and during a terminal cycle

whell a luatara reduces a cricket. Note the ditference in the

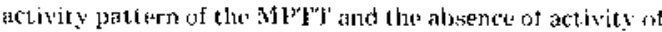
the MP'A during a terminal cycle. That numbers along the tisplacement graph indicate the six phases of a reduction cycte.

of these anterior teeth increases the vertical distance between the upper and lower tooth rows in this region; more important, it increases the effective height of the enlarged successional teeth (which show less wear) and per-

mits adult animals to impale larger prey. The few small remnant hatchling teeth provide a rough contact surface that will hold large prey; however, such prey must be repositioned before reduction. In adult Sphenodon, the small 
surface area of the remnant hatchling teeth limits their shearing capacity and thus this section is not used during reduction of large prey.

Our X-ray movies of feeding sequences suggest that Sphenodon lacks cranial kinesis and this observation agrees with some reports (Versluys, '12; Kuhn-Schnyder, '54; Jollie, '60). However, Romer ("56) described a movable articulation between the basipterygoid process of the basisphenoid and the pterygoid. Iordansky (66) considered a special metakinesis as a possible feature of the tuatara skull. One should realize that even cineradiographs of lizards with kinetic skulls have not provided measurable displacement of bones because of the limited resolution of available methods (Throckmorton, 76 ). Whatever the condition in juvenile animals (Ostrom, '62), manipulation of skulls and of living adults shows no trace of cranial kinesis. [Since the preparation of this report, one of us [C.G.| was able to examine two living specimens, each younger than 5 years. Neither showed any capacity for palatal motility.]

The pattern of food reduction seen in Sphenodon would seem to represent an interesting and important variant in the development of reptilian masticatory patterns. It is a rather specialized behavior, as most living reptiles use their feeding apparatus as an "organ of prehension" (Davis, '61). The most signifi. cant aspect is probably indicated by Robinson's comments ('76) about the "poor occlusal relationships." One could even modify this comment to state that Sphenodon lacks occlusion of the kind seen in mammals. The tooth rows do not meet but interdigitate. A staggered interdigitation of tooth positions may occur among the individual teeth of other reptiles (crocodilians are a good example), but Sphenodon shows an interdigitation of tooth rows, rather than of individual teeth. On each side of the mouth, the food is contacted by two sets of teeth on its dorsal and one set on its ventral surface. The close approximation of the pterygoid flanges and coronoid processes assures that the mandible can only move parallel to the upper tooth rows. The food object is thus exposed to short-distance bending or shear, the effect of which differs with the consistency of the prey. Consequently, we have here a foodhandling system unique in vertebrates.

The static forces applied to the dorsal and ventral tooth rows differ only slightly (the lat. ter is greater by the mass of the bolus). However, the tooth/prey contact area is likely to be greater on the dorsal (two rows of teeth) than on the ventral (a single row) surface. Consequently, the stress level will be much larger on the ventral side. This arrangement assures that the mandibular rather than the maxillopalatine teeth will first perforate uniform prey. The effects of mandibular deceleration and the closing forces will differ depending upon the position of the food. If the bolus moves with the mandible, deceleration forces will decrease the differential. If the tongue holds the bolus against the palate, the forces will enhance it.

As shear during sliding movements is again greater on the mandibular than on either the maxillary or palatine rows, the cutting action will also begin on the mandible. The asymmetry of anteroposterior edges becomes criti. cal during the propalineal translation at the end of crushing: the anteriad shift of the mandible then exposes the food to the sharply sloping vertical aspects of the three tooth rows. This angulation increases the probability that the cusps will hook into surface irregularities of the prey; the forward slide of the mandible thus induces localized shear and cutting.

In interpreting any of the several patterns seen, it remains critical to remember that the stress induced and the strain effected in the prey surface will be less when more teeth or a greater cutting surface contact the prey; other things being equal, prey deformation or rupture is thus greatest for the cutting element that has fewest contact points. This, of course, assumes that the translational movement $o$ curs while the teeth are pressed together, as they are in Sphenodon. Should the prey be impaled on the dentary or held against it by the tongue, it might then be slid past the palatine tooth array and its inertia would enhance rasping or cutting of its surface.

The crushing and shearing phases shown by Sphenodon have a markedly different significance for the two food types tested. In dealing with the exoskeleton of relatively large hard prey, the closing movement must effect a major force so that the teeth will induce initial penetration at high angles of incidence among teeth and prey. This initial perforation by the crushing action weakens the exoskeleton, as it provides stress-concentrating points; the shearing phase then rips apart the armor. Although we did not test prey items with truly heavy exoskeletons, the large orthopterans and beetles ingested by tuataras in the wild probably represent the kinds of prey for which this process in critical.

For soft prey, the relative significance of 
these two phases of each masticatory cycle differs. The initial bite then serves not only to crush and incapacitate prey but also to fold up the soft tissues, compressing them against the internal skeleton. To make the propalineal shearing movement effective, the direct crushing force must continue to be applied; thus compressors may be seen to fire at full level during the beginning of the sliding movement. (Continuation of compression during shearing may be visualized by considering the use of a sharp knife to cut a folded piece of fabric resting on a wooden block. If the blade presses the fabric against the block, and then slides along the surface, all pleats and folds will be separated simultaneously. If the knife only presses the cloth against the block in some regions, only these will be separated, the loose cloth will stretch and a much longer horizontal movement is required for its separation.) Thus, the effectiveness of cutting is markedly increased by holding the dorsal and ventral tooth rows together during the slide. The crushing also permits more rapid approach of teeth to the internal skeleton of the prey. When Sphenodon reduces adult birds or mice, the relatively short mandibular cusps are unlikely to reach bone until several shearing strokes have occurred.

The combination of the crush-induced holding action and of the differential stress levels noted at the upper and lower tooth rows have major effects on the length of the stroke needed for penetration. As the jaws close, the distance between them decreases. This changes the force application to the bolus from long bending to shear and increases the risk of local failure of the integument and of the soft tissues in the prey. The greater local stresses imposed by the mandibular teeth are more likely to exceed the elastic limit of the prey than are the lower stresses induced where the bolus contacts the upper jaw. Thus, the bolus is likely to hang on the palatal surface and cutting will be concentrated between bolus and mandibular teeth. This means that the full anteriad stroke of the mandible induces a cut at a single site of a fixed prey item. It assures maximal utilization of the rather limited capacity of the mandible for propalineal movement.

Both the crushing and the shearing mechanism make the continuous posterior shift of the prey advantageous. First of all, posterior shift of the prey improves the effective moment arm of the jaw. Secondly, the acrodont dentition only adds additional cusps at the rear; this assures that the posterior teeth are larger, less worn. and better able to perform the slicing action. There may be a trade off as very large prey would, when placed between the posteriormost teeth, require a very wide gape and thus place the crushing muscles into a less advantageous portion of the length-ten. sion curve. This may be the reason why some of the dorsalmost crushing muscles (M. ad. ductor mandibulae externus medialis, M. pseudotemporalis superficialis) have relatively long fibers that curve ventrolaterally and only start to fire effectively after the mouth has partially closed. The placement of the pterygoid muscles suggests that their activity should not shift on the length-tension curve, as displacement is relatively independent of gape (see below).

\section{Capture}

Sphenodon uses different approaches to capture small and large prey. Small prey are re trieved by rapid movement of the tongue, pulled into the back of the mouth and bitten in itially between the cheek teeth. Large prey are captured by moving the head toward them, biting them while the tongue remains at rest and impaling them on the incisor-like succes. sional teeth. The difference may involve several factors.

Small prey are relatively flat and their bodies tend to be close to the ground; this would force the tuatara to bend its neck sharply in order to bring the jaws into position for the bite. Most small prey, such as crickets and cockroaches, are also very mobile and acceleration of the tongue is less costly (and hence likely to be more rapid) than that of the entire head. The adhesive mechanism for prey capture is in. herent in the dorsal surface of the tongue and is reflected in its long, densely packed papillae and mucous cells (Gabe and Saint Girons, '64); these give the tongue the appearance of a deeppile carpet. Sphenodon rarely uses its tongue during the capture of large and slowly crawling prey, such as juvenile mice. Sphenodon then moves its snout close to the prey, opens its mouth, and shifts it into position for a bite. The projecting successional teeth will hold the soft prey, even when the initial bite does not otherwise incapacitate it. Thus, Sphenodon captures prey with a pattern reflecting prey size, configuration, and mobility.

Transport of prey also reflects its size, weight, and texture. Small prey is transported by the tongue; Iarge prey is shifted by inertial movements of the head. I arge prey occupies much of the oral cavity and thus limits move- 
ments of the tongue. Also, feathered and furred prey provide poor surfaces for lingual adhesion.

\section{Reduction}

Sphenodon reduces both small and large prey with similar mandibular movements. Two factors that may explain this stereotyped pat. tern of movement are: 1 t the limited degrees of freedom of the cranial joints force the movements to follow a set path, and 2 ! the activity pattern of the muscles generating the movements remains relatively constant throughout reduction sequences.

In Sphenodon, the degrees of freedom of the mandible are indeed limited by the position of the tooth rows and the close approximation of the pterygoid flanges and coronoid processes; this would by itself tend to produce the repeatable movement pattern observed. However, even though the pattern of movement remains relatively constant, other aspects of the masticatory cycle, such as motor activity. change with food type (Tables 2,3); so does the degree of head and tongue movement. Thus. whereas mandibular excursion is stereotyped because of the constraints of the hard tissues and absence of intracranial movement (kinesis), the size and consistency of the food have significant effect on movements of the head and tongue.

Throckmorton (76) suggested that the slow opening may be assisted by gravity. Iowever. duration of the slow-opening phase during reduction of juvenile mice (weight 6-7 $\mathrm{gm}$ ) is twice that during reduction of crickets 10.3-0.6 $\mathrm{gm})$. If slow opening were gravity-assisted, it would be more rapid during the reduction of heavier than of lighter prey items.

The duration of the slow-opening phase does reflect the size of the fond. Obviously, large prey occupies more space within the oral cavity than does small prey. Perhaps, as there is less space to manipulate it. the risk of loss is greater. However, prolongation of the slowopening phase increases the length of time the prey is secured and decreases the risk of losing it. By opening the mouth slowly and for a short distance beyond the diameter of preyl. Sphenodon can quickly snap it closed to keep prey from slipping out of the mouth.

\section{Terminal}

During terminal movements, Sphenodon uses its tongue to clean the oral cavity in two different ways. After reduction of crickets and cockroaches, Sphenodon seems first to clean the anterior part of the tongue by passing it between the tips of the upper and lower jaws, and then clean the floor and roof of the mouth by arcing the tongue and moving it posteriorly. After mice are reduced, Sphenodon again uses the jaw s to clean the tongue first but then uses the tongue to clean only the floor of the mouth. Perhaps the fluid content of mice does not adhere to the roof of the mouth, sliminating the need to clean it: also most cutting action takes place along the ventral surface of the prey.

\section{General \\ Myology and electromyography}

The review of Haas ('73) indicates that the head muscles of Sphenodon are similar to those of a generalized lizard, but retain some indications of arrangernents primitive among reptiles. The tuatara differs from squamates in having an anterior M. pterygoideus atypicus. Also the separation among adjacent muscles is less pronounced in Sphenodon than in lizards or snakes (Haas, '73). The latter condition may reflect an absence of mobility among cranial elements, but it also raises the question whether the muscular separation is retained from an earlier form with a less rigid skull. Al ternatively one may ask whether the described subdivisions are real or based upon expecta. tions derived from the study of squamates. For instance, the two posteriormost portions of the $M$. adductor mandibulae externus medialis may be defined morphologically and have slight differences in fiber direction (and fiber length); however, their activity shows no sig. nificant differences. In contrast, the $M$. depressor mandibulae and $M$. adductor mandibulae ex ternus superficialis sensu stricto are not morphologically separated into distinct portions, but their sections do differ in fiber length and in activity pattern.

In Sphenodon, the anterior movement of the lower jaw during the shearing phase is an im. portant component of mastication. The $M$. pterygoideus typicus is the largest single muscle and its anteroposterior line of action directs the forces primarily anteriorly and to a small degree vertically and horizontally, even when the mouth is wide open. Thus, although the MPTT is active during crushing, its maximum activity levels during reduction occur during the shearing phase, when movement of the lower jaw follows the main line of action of the muscle. Furthermore, the fixed quadrate of Sphenodon would keep the main line of action of the MPTT in a constant anteroposterior 
line. Smith ('80) notes the forward movement of the quadrate and activity of the $M$. pterygoideus of Varanus during closing. She argues that a movable quadrate lets the $M$. pterygoideus function as an adductor during ingestion, and moves the lower jaw anteriorly during biting. However. Sphenodon also has a large M. pterygoideus, which clearly facilitates the generation of large forces during the shearing phase. Even though the M. pterygoideus of Varanus may assist in closing the mouth, its size and primarily anteroposterior line of action suggest additional functions. Size and position indicate that the muscle would tend to generate large propalineal forces during the bite. These would be less important in shifting the lower jaw than in maintaining its position relative to the midline when prey is struggling or being shaken.

\section{Capture}

The activity pattern of most of the muscles studied differs between the times during which Sphenudon makes a capture bite and those in which it engages in reduction cycles. These differences seem to reflect the need to 1 l open the mouth rapidly during the capture bite (so that the congue can be quickly protruded), and 2) then to snap the mouth closed to secure and kill the prey. Opening for a bite proceeds uni. formly and fast: the slow-opening phase characterizing reduction, terminal, and repositioning cycles is then absent. Consequently, both portions of the $M$. depressor mandibulae become active bilaterally: in contrast. only the anterior portion of the muscle is active during slow opening. 'The simultaneous firing at the start of opening not only rotates the mandibles, but also induces posterior translation of the fossa on the condyle, so that the mandible drops most rapidly.

The closing movement is similarly distinct. Not only do the various adductors fire more symmetrically during capture than during a reduction bite. but the $M$, pterygoideus immediately becomes active symmetrically. It contributes to the closing component and thus accelerates the jaw and adds to its impact, but it also induces maximum propalineal action at the very beginning of closure. This brings the successional teeth into opposed position so that they approach each other before closure. rather than at the end of the shearing phase.

\section{Reduction}

In Sphenodon, slow opening is generated by the anterior portion of the $M$. depressor mandi- bulae (MDM). 'The nearly vertical path of these fibers to their insertion just posterior to the quadratoarticular joint would simply rotate the mandible about the quadratoarticular joint, opening the mouth straight downward. In the herbivorous lizard Uromastyx the MDM inserts at the caudal end of the lower jaw. well posterior to the jaw joint; it is silent during slow opening (Throckmorton, '78). This position and activity pattern are similar to those of the posterior portion of the MDM in Sphenodon. These results suggest that those fibers of the MDM lying close to the joint may induce slow opening of the mouth, whereas those lying farthest away from the joint induce fast opening. Consequently, studies on reptilian feeding should examine not only various subdivisions of the complex adductors, but also different areas of comparatively simple muscles, such as the MDM.

During a reduction cycle, the activities of the superficial and deep adductors and the ptery. goids allow them to be classified into three functional groups Fig. 10). The first is the closing-compressor group. It consists of the M. ad. ductor mandibulae externus superficialis, the M. adductor mandibulae externus profundus, and the $\mathrm{M}$. pseudotemporalis superficialis. The second group is the compressor-shear group. It consists of the M. pseudotemporalis profundus and the M. pterygoideus atypicus. "The third group is the shear group and it consists of the M. pterygoideus typicus. Group I generates closing forces that initially close the mouth and then compress or crush the prey. Group 2 generates compressive forces during crushing but continues to apply these forces during shearing. Simultaneously, group 3 induces anteriorly directed forces on the lower jaw and the food is compressed and sheared by action of groups 2 and 3. The activity levels of the ad. ductors apparently reflect instantaneous local changes in tension due to changes in the consistency and position of the bolus during reduction cycles.

Olson (61) contrasted the concepts of "static pressure" and "kinetic inertial" systems of jaw mechanics. In the former the adductor muscles exert maximun force when the mouth is nearly closed and thoroughly reduce the food. In the latter, the adductors supposedly exert maximum forces when the mouth is wide open, food is not reduced and the muscles apparently function for prey capture. In Sphenodon, the activity level of the adductors generally supports the concept of a "static pressure" system. However, the activity levels generated by the 


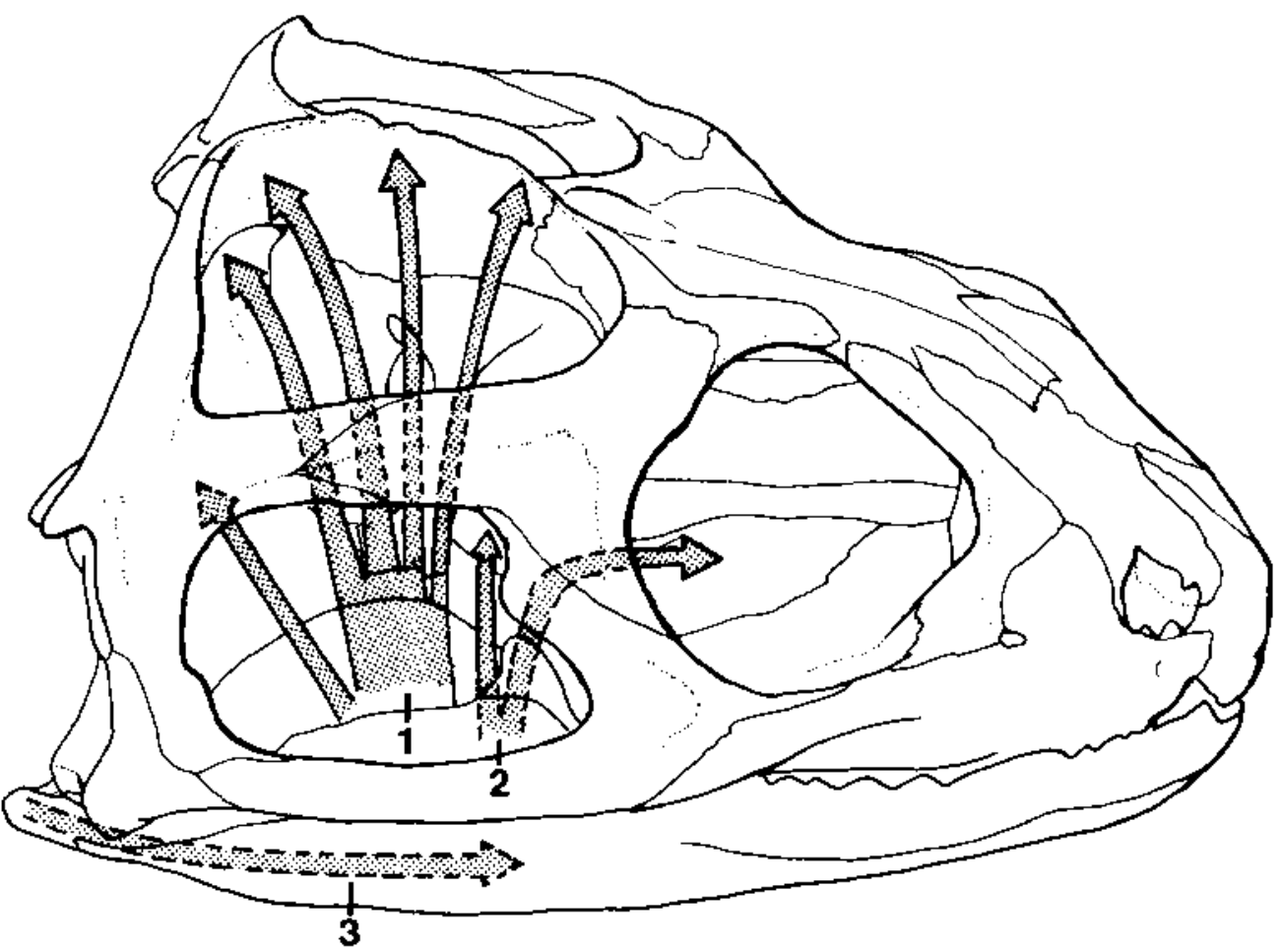

Hig. 10. Sphenodion purstatus. Iateral siew of the skuld showing at summary of the three nechunical adductor

adductors of both the working and balancing sides change from bite to bite during a reduction sequence: presumably these muscles respond to changes in the position and texture of the bolus. (This pattern is equivalent to that shown by some masticating mammais.) Thus, the present results support the hypothesis of a "static pressure" system only in that forces exerted by the adductors during an individual bite are greatest when the mouth is nearly closed. However, they conflict with the hypothesis in that the forces generated by the adductors during a bite are not the maximum forces that these muscles are capable of exerting, nor are the forces generated then equivalent among hites of a reduction se quence. The concept of "maximum " force involves too many variables to be meaningful in this context.

In the reduction cycles of Uromastyx aegyptius, the M. depressor mandibulae (MDM) is active when the mouth cioses and the deep portion of the M. pterygoideus (MPTT) is active when the mouth opens (Throckmorton, '76); groups. 1, Closing-compressor group; 2, compressor-shear सroup: 3, shear group

these thus differ from activities recorded in Sphenodon during reduction. These differing activity patterns seem to relate to the degree to which the quadrate can move. In Uromasty $x$, the guadrate is held only by supratemporal and pterygoid. Thus, action of the MDM and MP'TT not only moves the mandible about the quadrate but also increases mandibular excursion by movement of the quadrate itself; these muscles may also function to stabilize the quadrate. In Sphenodon, the quadrate is fixed and mandibular movements are restricted to the quadratoarticular joint. Consequently, the activity patterns of at least the MDM and MPTT are apparently affected by the degree of cranial kinesis. Unfortunately. we still lack detailed descriptions of feeding movements and the activity patterns of the other masticatory muscles in Uromastyx aegyptius or other lizards that show varying degrees of cranial kinesis. Thus, comparisons relating the degree of intracranial movements and the activity patterns of the masticatory muscles are premature. 


\section{Terminal}

The fibers of the middle portion of the $M$. pterygoideus typicus (MP'"T) lie anteroposteriorly when the mouth is closed; activation of these fibers would then tend to pull the mandible directly anteriorly. During terminal cycles, activity of the ventrolateral and medial and la. teral deep parts would bring the tips of the upper and lower jaws into close approximation, but would not generate significant closing forces on the mandible. Such activity, while the anterior part of the tongue pushes against the aligned tips of the jaws during terminal cycles, allows the mouth gradually to open while conforming to the shape of the pro. truding tongue: the incisor-like teeth are then rubbed against the surface, eleaning the tongue.

The fiber direction of the medial and Jateral superficial parts of the M P'T' suggests that it would also tend to move the mandible anteriorly when the mouth is closed and that it would maintain the closed position. However, during terminal cycles the supertictal part of the MPT'T is active coincident with the $M$, depres. sor mandibulae (MDM) as the mouth opens. Simultaneously, activity of the ventrolateral and lateral deep parts increases. Their actions form a bilateral force couple. These parts of the MP'T and the MDM insert as a sling on the posterior end of the articular. Upward pull by the MDM rotates the mandible about the quadrate while the anterior pull of the MPTT limits posterior translation of the mandible. Consequently, the mandible opens by simple rotation, accounting for the decrease in propalineal movement during terminal cycles.

\section{Fiber length relationships}

While the fiber lengths of the museles considered in this study differ by a ratio of almost 6 to 1 , the extreme lengths are represented by only three muscles. The dorsalmost (deep) portions of the M. pterygoideus typicus and the M. adductor mandibulae externus profundus have the shorlest fibers and the posterior portion of the M. depressor mandibulae has the longest ones (Table 1). However, most muscles show a wide range of fiber lengths, with the exception of such muscles as the M. pterygoideus atypicus. Fiber lengths generally differ within subdivisions. This variability emphasizes the importance of sampling many sites before assuming that the fiber length is constant.

When the fiber lengths are viewed in relation to their position and activity times, a very in- teresting pattern emerges. The first example is given by the anterior and posterior portions of the $M$. depressor mandibulae. The fibers of the anterior portion are shorter than the posterior ones. The anterior portion also inserts close to the quadratomandibular joint and thus has a short moment arm. This anterior portion fires during slow opening, inducing initial separa. tion of tecth from the bolus. The muscle then appears to be close to its resting length: however, the length-tension relation may not be particularly critical, as the muscle is then active only at a low level. Initially the teeth are still embedded in the food and the muscle induces pure rotation. After the start of the fast. opening phase, muscular activity increases and contributes to further opening: however. at this time the muscle incurs a slight relative lengthening as the mandible is translated posteriorly at the jaw joint: this might improve the length-tension relationship.

The more posterior portion of the $\mathrm{M}$. depressor mandibulae not only has a longer lever arm and much greater bulk, but has markedly longer fibers than the anterior portion. The former is active only when the nandible is being rapidly depressed. inducing both rotation and transhation. Quite clearly the much greater length of its fibers reduces relative shortening and retains the muscle in the advantageous portion of the length-tension curve.

Similar patterns are seen in the fast closing and crushing movements. The anteriormost portions of the MAMES have long fibers and the MAMFP has relatively short ones, although both muscles start the fast-closing movement. The MAMEP has a relatively short lever arm, but the fibers of the MAMES lie superficially along the side of the face and have a relatively long lever arm. 'Toward the end of fast closing thefore the cusps reach firm contact with the preyl, one notes the start of ac. tivity 1) of the posterior portion of the MAMES, 2 of the three portions of the MAMEM, and 3) of the MPTS. Four of these five muscles show similar and relatively narrow ranges in fiber lengths, and the other (MP'TS) shows a wide range. The MAMEM-a has the shortest fibers and lever arm of the MAMEM complex; the posterior portion of the MAMES also has shorter fibers and lever arm than the anterior one. 'The short fibers of the MPTS reach from the parietal straight ventrally to the basal aponeurosis, whereas its long fibers curve laterad and then run ventrad. The long fibers of the MAMEM also curve ventrolaterally and will in the resting position form 
an angle of close to $40^{\circ}$ in their course. Apparently these curving fibers are much straighter when the mandible is fully depressed. 'l'hus, those adductors in which the direction of action is straight dorsoventral have short fibers and those in which the path of the muscle incurs a curve to a more posteriorly displaced origin have long ones. Furthermore, in spite of their different origins, the lengths of most fibers of the MAMEM and MPTS are similar, though the latter has a group of deeply placed, short fibers. These similarities appear to be achieved by the attachment of these muscles on various continuations of the basal aponeurosis rather than directly on the mandible.

In the M. pterygoideus typicus (MPT'T) the origin of the fibers varies, whereas all of them insert in close juxtaposition. Thus, there is a regional change in fiber arrangement from long-fibered parallel to short-fibered bipinnate. The long-fibered portion is apparently capable of greater absolute shortening than the shortfibered one. It is activated before the short one and induces the initial propalineal forces during shearing. In contrast, the short fibers induce the forces at the end of the shearing phase. The long, medial fibers would also induce a medial component to the force, which may be disadvantageous for generating propalineal movement. The medial component would shift the jaw very slightly toward the working side at the start of shearing when the teeth are slightly separated. However, the line of action of the short, lateral, bipinnate fibers is nearly straight anteriorly and parallel to the toothrows. Thus, at the end of the shearing phase these fibers tend to keep the lower teeth aligned between the upper rows while generating a tinal thrust to shear the food. The fiber arrangement and parallel arrangement of long and short fibers do raise some questions about preliminary firing patterns that may bring the fibers to a length at which stimulation will induce effective action.

\section{Neural control}

Little is known about the neural mechanism controlling the feeding movements of lizards and of the activity patterns of the muscles generating them. Almost all work on the neural control of mastication has been carried out on mammals (Dubner and Kawamura, '71; Gans et al., '781. Three observations relate generally to control systems and may deserve brief mention.

The duration of the different phases of a reduction cycle is affected by the size of the food object. Similarly, the activity levels of the adductors reflect the size and position of the bolus. The increased adductor activity, when food is in contact with the teeth, suggests that the timing and level of adductor activity are controlled by an oral afferent feedback system. Whether this feedback system is similar to that of mammals remains subject to test. The present observations suggest the likelihood that the afferent information on the size and position of the bolus is derived from the sense organs of the tongue.

The masticatory muscles of Sphenodon do not have to restrain the jaw movements to the propalineal plane, as the mechanical constraints preclude lateral movements. In lizards with cranial kinesis, the muscles presumably have a greater role in guiding the movements of the jaw and in stabilizing cranial elements during the bite. One would expect more complex control systems in such cases.

In spite of this mechanical simplicity, the neural control mechanism in Sphenodon appears to be relatively complex. Olfactory cues mediate the prey attack response and visual cues are used to steer the capture of prey. 'The size and position of the bolus are monitored during reduction and will affect the activity of the masticatory, lingual, and nuchal musculature. These oral sensory signals steer not only the overall food handling, but are obviously responsible for differences between the EMG patterns of successive cycles.

\section{Phylogeny}

'The capacity for inducing not only perforating and crushing forces but for applying shear in an anterior-posterior direction may be critical in the further development of sphenodontid dentition, as well as in that of the rhynchosaurs (which may or may not be related to Sphenodon: Carroll, '77; Sill, 711. These animals tend to widen the maxillary palantine tooth area in which each row is composed of an array of variously shaped teeth. The mandibular tooth row is much narrower and its teeth perhaps larger, a pattern that has been variously ascribed to adaptation to a herbivorous diel. Cutting action by the upper teeth would presumably require that the food object move past them. This cutting action could occur only if the prey were impaled on dentary teeth and cutting-slippage occurred against the palatal surface. The effect here would be equivalent to those achieved when the tooth cusps are widened and serve as slic- 
ing or shaving devices while they move at right angles to the prey.

Although this study does not deal with fossils to any significant extent, the pattern in Sphenodon permits some very interesting speculations. Most textbooks argue that heterodonty and complex tooth shapes are characteristic of mammals and absent in Recent reptiles. While this is an overstatement (Edmund, 69\%. the pattern of manditular movement is obviously more complex in modern mammals. 'The nature of the complexity generally reflects translatory movements between the tooth rows.

Such translation has apparently arisen a number of times independently. 'Thus, it occurs in turtles (Gaffney, 75), in Sphenodon, and presumably within the therapsid-mammalian transition. In each case, this horizontal movement apparently involves sliding along the craniomandibular joint and is independent of the phenomenon of cranial kinesis. The latter primarily reflects movement between and about the occipital. the medial, and the nasal portions of the braincase, as well as between the variously fixed dental arcades and the quadratic suspension of the mandible.

While translatory movements do occur in some turtles, the broad crushing surfaces and continuous cutling edges of the Testudines would involve few problems with occlusion. The occlusion of dental arrays is assumed to be much more difficult to develop and in vestigators bave predicated a complex series of stages with gradual development of additional cusps and basins (Peyer, 68 ).

'The solution found by the Rhynchocephalia (and rhynchosaurs) appears to reflect a rather simple avoidance of the occlusion problem. The teeth need never contact, and the wear marks between them are as likely to reflect interaction of tooth and prey as grinding of tooth on tooth. The system is effective even when the inter-row distance changes. Local variants in tooth shape have much less effect than do those in mammals. In this sense, one can assume that these small reptiles developed a food niche that was later to be expanded by mammals.

While we see an initially equivalent solution, the pattern also incorporates a profound future limitation. As long as the mandible has to slide between maxilla and palatine, it is restricted to strict propalineal movements. Reptiles with such a pattern are therefore precluded from shitt to any of the transverse masticatory types that proved so successful in mammals.
More important, the avoidance of the need for a precise matching bite eliminated any tendency for later development of different kinds of "molar occlusions." The dentition in the sphenodontid upper jaw may be conceived as a mammalian molar row with a medial separation. It presumably represented a significiant advance over a general crushing bite, but the solution adopted may have blocked the path to continuing development.

\section{ACKNOWLFIMI\}LN'I'S}

The preserved specimens derive from the collections of the American Museum of Natural History (AMNH, R.G. Zweifelt, that of Cornel] University (CU, H. I'ough), and the Carl Gans collection at Ann Arbor (C.G.). We thank curators for facilitating loans and Dr. R.G. Northcutt for the gift of dissected specimens. We acknowledge grant BMS 7101380 from the U.S. National Science Foundation (C.G.), grant DHEW-PIS-G-IRO1DE05112 from the National Institutes of Health IC.G. and G.C.G.), and grant A-6062 from the Natural Sciences and Engineering Research Council of Canada (H.R.). Cinefluoroscopy was carried out at the Museum of Comparative Zoology facility of Dr. F.A. Jenkins with the assistance of Miss E. Gordon. We thank B. Clark. C. leonard, and $T$. Scanion for their aid with the experiments; ' $T$. Rizki for provision of a reference; F. de Vree and A.P. Russell for comments on the manuscript: $J$. Beach and J. Fetcho for developing the computer software; and D. Iuce and Teryl Lynn for preparing the andtomic illustrations.

\section{II'ERATURE, CITED}

Bock. M.J., and C..K. Shear 11972) A stuinong method for gross dissection of vertebrate mukcles. Anat. Anz. $130-222-227$

Byeriy, 'T.C. [1925) 'The myology of Sphenodon puntatum. U. lowa St.ud. Nat. Itist, 11(6):-3-51.

Carroll. R.I. (1977) The nrigin of lizalrds. In S.M. Andrews K.S. Msles, and A.J). Wilker (eds.): Problems in Vertebrate Fvolution. I.innean Soc. Symp. Ser. So. 4, pp.35y-396.

(undal], J)., and C.. (ians (1979) Feding m water snakes: An แert,omyographic study. J. Exp. Zool. 209.189-208.

Cronk, I.G, 11975) The tuatsas in (i. Kuschel tedt: Biogeography and Foology of New Zealand. 'l'he Hagut Momogr uphie Bial. Junk., Vul. 27, pp.331-352

Davis, D.D. 11961 , Origin of the mammalian feeding mech anism. An. 7ool. 1.229-234.

T)awbin, W.H. (1962) The tuatara in its natural habitat. Endeavour $21: 16-24$.

Lubner, R., and Y. Kawamura, uds. 11971 (1 Oral-Facial Sensory and Hotor Hechanisms. Sew York; Applaton Ceritury Crofts. 
Edmund, A.G. 11969) Dentition. In C. Gans and T.S. Par sons feds.): Biology of the Rtptilia. London: Academic Press, Vol. 1. pp.117-200

Frazzelta, T.11. 11962) A furctional consideration of cranial kinesis in lizards. J. Morphol. $1 / 1: 287-320$

Githe, M., and It. Saint Girons 11964\} Contribution a l'histologie de Sphomodon punctuts.s (iray. Paris: Edit. Cent. Nat. Rexh. Sci.

Gaffney, F.S. 11975$\} \wedge$ phylogeny and classification of the higher categories of turtles. Bull. Am. Mus. Nat. Hist. 1.3.5:389-436.

Gans, C. (1961) The feeding mechanism of snakes and its possible evolution. Am. Zool. 1:217-227

Gans, C. (1966) An inexpensive arrangement of movie: camera and electronic flash ds a tonl in the study of animal behaviour. Animal Behav. 1411: $1 \mathrm{I}-12$.

Gans. C. (1974) Biomechanics, An Approach to Vertebrate Biology, Philadelphia: J. 13. Lippincote Co. (Now Univ. of Michigan Press.]

Gans, C. (1982) is Sphenodon punctatus a maladapted relict? Bull. Mus Comp. Zool. IIarv. Lniv.

Gans, C.. and G.C. Gorniak $\{1980$ ) Flestromyorrarss are repeatable: Precautions and limitations Serence 2) $10: 795-797$

Gans, C, and F.G. Wever $\{1976\}$ Ear and hearing in Sphomedon punctatus, Proc. Natl. Acad Sci. LSA $23.4244-4246$

Gans. (.. F'. De V'ree, and (i.C. Gorniak (1978) Aralysis of mammalian masticatory mechanisms: P'rokeress and prob]ems. Anat. Histol. Etnbryol. 7:226-244.

Gornak, (i.C., and C. Gans (19k0) Quantilatise assay of plectromyograms during mastication in domestie cats (Felis ratus). J. Morphol. 16.1:25;3-281.

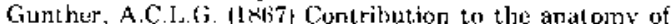
Matteria tRhynehoerphades, Owent. Phil T'rans. R. Sot:Ionti. $157(2): 595-629$.

Hads, Ci. 119731 Muscles of the jaws and associated struclures in the Rhynchocephalia and Squamata. In C. (ians and T.S. Parsons feds.t: 13iology of the Reptilia. Jondon: Acadetnic Press. Vol. 4, pp. $285-490$.

Hill, L.. and W.IL. Daubin 11969 . Nitrogen excretion in the? tuatara. Sphenerlon punctafus. Comp. Buochem Physiol. $31.433-468$.

lordansky'. N. X. 11966$)$ Cranıal kınesis in lizards: cuntribution $w$, the problem of the adaptive signific ance of skull kinesis. Zool. Zhur. 45:1:398-1.710.

Ireland, I..C., and C. Sians11977) Optokinet ic behavior of 1 he tuatara, Sphtsoton puncfatus. Herpetolofica $33: 339-344$
Jollie, M.T. (1960) 'The head skeleton of the lizard. Acta Zool. $11: 1 \cdot 64$,

Kuhn-Schnyder, F. (1954) The origin of lizards. Endeavour $13: 213-219$

Mclonald, HS. and J E, Heath 11971 Flectrocardicgraphic observations on the tuatara, Sphenudon purc. tous. Comp. Birchem. Physiol. 40A $481-K 92$.

Olson, E.C. (1961) Jaw mecharisms: Rhipidistians. amphibians, and reptiles. Am. Zool. 1:205-21 is.

Ostrom. J. (1962) On the constrictor dorsalis muscies of Sphenodon. Copeia 1962:732-735.

l'eyer. H. $\{1964\}$ R. Zangerl (trans, and ed.): Comparative Odontology. Chicago: Liniversily of Chicugo Press.

poglayen-Neuwall, I. 199531 Untersuchungen uber die Irigreminusmuskutatur von Hatteria. Z. Wiss. Zool 1 1; $757-76$

Rieppel 0.11978, 'The phylogeny' of cranial kinesis in lnwer vertebrates, with special reterence $\omega$ the Lacertilia. Neues Jahrb. Geol Palaeontol. Abh. I:56:353-370.

Rohb, d. (1973) Keptiles and amphibia. In G.R. Williams (ed.J: The Natural History of New Zeatand. A H. \& A.S Reed l3ooks. pp. 285-3033.

Robb, J. 119771 The Tuatara, Fingland: Meadowfield Prexs Ltd.

Robinsen, P. 2. 11973) A problematic reptile from the British I Ipper 'Trias. J. Geol. Soc. lond 129.157-479.

R(ubinson, P.L. 11976) How Sphenuden and Uromastyx grow their teeth und use them. In $A d^{\prime} A$. Bellairs and C. B. Cox led.s.: Morphology and Biokgy of Ruptiles. Linn. Soc Symp. Ser.. Vol 3. pp.433-64.

Ronver. A.s. 11956 ) Osteology of the Reptiles. Chicago: Lni versily of Chicage Press.

Sill, W'L 11971 , Functional morphology of the Rhyncho. saur skull. Forma Functio $1.303-318$.

Smith, K. 11980 / Mechanical significance of streptostyly in lizards. Nature $2 \times 37774-779$

Throckmorton, (3.S. (1976) Oral food processing in two her bivorous licards. Iguano iguana liguanidae and Ciromastix argyetiss Agamidarl. J. Morphol. $14 \times: 363-390$.

Throckinorton, (i.s. 11978 Action of the pterygoideus mus. cle during feeding in the lizard Lromastix aegrytius

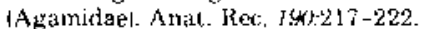

'T'hrockmorton, (j.S. 11980 ) The chewing (yele' in the herbi vorous lizard Viromastyx aegyptius A Agandaet Arch. Oral biol. 25:225:233.

Versluys, J. (It3I2) Das Streptostylite-I'roblem und die Bewegungen im Sichadel bel Sauropsiden. Zool. Jahrb. ISuppl.) 15:545 $716 \mathrm{i}$ 